\title{
Immediate and Long-term Memory and Their Relation to Crystallized and Fluid Intelligence
}

David Martinez

School of Psychology, Georgia Institute of Technology

This is a preprint of an article published by Elsevier in Intelligence available online at https://doi.org/10.1016/j.intell.2019.101382

Martinez, D. (2019). Immediate and long-term memory and their relation to crystallized and fluid intelligence. Intelligence. https://doi.org/10.1016/j.intell.2019.101382

Acknowledgments:

This research was supported by National Science Foundation award \#1651115. Many thanks to Dr. Jenny Singleton, Maya Berinhout, Stephanie Blough, Lindsey Drummond, Morgan Foreman, Skyler Tordoya-Henckell, Kevaghn Hinckley, Sidni Vaughn Justus, Rachel Monahan, Elizabeth Pierotti, and Angelique Soulakos for their support. Additional thank yous to Carmen Winkler for help editing and the anonymous reviewers for their wonderful and very swift feedback.

Corresponding author: David Martinez, Applied Research Laboratory for Intelligence and Security, 7005 52 ${ }^{\text {nd }}$ Ave, College Park, MD 20742. E-mail: DMartin5@umd.edu 


\begin{abstract}
The present study was conducted to investigate associations between Gc and Gf and several memory factors - namely short-term memory (STM) span, working memory capacity (WMC), and declarative long-term memory (dLTM) ability. Two hundred and thirty-six individuals completed a number of tasks assessing the above named constructs and structural equation models were fitted. In line with prior research, both WMC and dLTM ability directly accounted for variance in Gf. Notably, these same factors also accounted for variance in Gc. Importantly, however, the results of two exploratory analyses suggest that WMC and dLTM ability explain variance in Gc that is due to the investment of Gf. These exploratory analyses raise doubts about the purported role of dLTM ability in Gf and Gc performance. Ultimately, it is argued that there is need for further research investigating the cognitive components of Gc as well as dLTM ability.
\end{abstract}




\section{Immediate and Long-term Memory and Their Relation to Crystallized and Fluid Intelligence}

...intelligence is a familiar part of everyday life...It's the set of skills that infuse and fuel our ability to navigate the world we inhabit; it is our ability to problem solve, to learn, and to organize bits of information that otherwise may seem disparate and incongruous. (Boutwell, 2018, p. 2)

Intelligence is not the amount of information people know, but their ability to recognize, acquire, organize, update, select, and apply it effectively. (Gottfredson, 1997, p. 93)

As Boutwell notes in the quote above and numerous studies have supported (e.g., Batty, Deary, \& Gottfredson, 2007; Diehl, Willis, \& Schaie, 1995; Gordon, 1997; Postlethwaite, 2011; Sternberg \& Kalmar, 1997; Wraw, Der, Gale, \& Deary, 2018), intelligence plays an important role in everyday life. Appropriately, a great deal of effort has been made to understand human intelligence, particularly general mental ability, or $g$ (Spearman, 1904), and the facet of intelligence that supports problem solving and reasoning: fluid intelligence (Gf; Cattell, 1943). However, as demonstrated by both quotes above, particularly Gottfredson's (1997) statement, this emphasis on $g$ and Gf has come at the expense of another major facet of intelligence: crystallized intelligence (Gc; Cattell, 1943), or the knowledge one has accumulated throughout life.

As a facet of intelligence, Gc is highly correlated with other intelligence factors, particularly Gf, but it is distinguishable at a number of levels of analyses (Carroll, 1993; 
Christoforou et al., 2014; Colom et al., 2009; Horn \& Cattell, 1967; Salthouse, 2004; Schroeders, Schipolowski, \& Wilhelm, 2015). Moreover, Gc independently accounts for a variety of outcomes and is often the superior predictor (Beier \& Ackerman, 2005; Postlethwaite, 2011; Thorsen, Gustafsson, \& Cliffordson, 2014; P. C. Williams, McCallum, \& Reed, 1996), and likely continues to increase in importance throughout adulthood (Ackerman, 2000) when compared to Gf.

With the above in mind, the present study was conducted to (1) investigate relations between Gc and memory—specifically short-term memory (STM) span, working memory (WM) capacity, and declarative long-term memory (dLTM) ability—and (2) replicate prior work examining relationships between Gf and memory. The aforementioned memory factors have been quite popular amongst researchers interested in the cognitive components of $g$ and $\mathrm{Gf}$ (see Ackerman, Beier, \& Boyle, 2005; Unsworth, 2019), however, comparatively fewer individual difference studies have examined relationships between these memory factors and Gc (e.g., Colom, Rebollo, Abad, \& Shih, 2006; Dang, Braeken, Colom, Ferrer, \& Liu, 2014; Dang, Braeken, Ferrer, \& Liu, 2012; Haavisto \& Lehto, 2005). Those that have been conducted, typically only include one or two memory factors, making it difficult to infer whether relationships are unique or due to common mechanisms, as STM span, WM capacity, and dLTM ability are all positively correlated (Kane et al., 2004; Shipstead, Lindsey, Marshall, \& Engle, 2014; Unsworth, 2019; Wilhelm, Hildebrandt, \& Oberauer, 2013). While studies investigating Gf and memory are more plentiful, it is also the case that researchers tend to investigate only a subset of the forenamed memory factors and their relation to Gf. The sections that follow provide relevant background on the constructs under consideration and the theories that guided the present work. 


\section{Background}

\section{Fluid and Crystallized Intelligence}

There are numerous theories of intelligence. Some posit a single general mental ability

(i.e., g) that suffuses all cognitive endeavors and therefore causes cognitive abilities to be positively correlated (e.g., Carroll, 1993; Johnson \& Bouchard, 2005; W. J. Schneider \& McGrew, 2018; Spearman, 1904) while others do not (e.g., Cattell, 1943; Horn \& Cattell, 1966; Jung \& Haier, 2007; Kovacs \& Conway, 2016; Thurstone, 1938; Van Der Maas et al., 2006; Van Der Maas, Kan, Marsman, \& Stevenson, 2017). The most relevant to the current study is the theory of Gf and Gc.

The theory of Gf and Gc, as originally proposed by Cattell (1943), was a hierarchical model of intelligence that rejected the notion of a single general mental ability in favor of two broad factors, namely, Gf and Gc. According to Cattell (1943, 1987), Gf is a biologically-based cognitive ability (though influenced by environmental factors); it is the broadest factormeaning it affects performance on the greatest number of variables — and is implicated in all tasks that can be benefited by perceiving novel relations. Gc, on the other hand, originates in the environment but is acquired through the action of cognitive processes, particularly Gf, and other non-cognitive variables (e.g., interest); it is the second broadest factor, influencing performance in proportion to the degree that one can deploy previously learned knowledge and skills. While Horn and Cattell (1966) added several other broad factors, Cattell (1987) continued to view Gf and Gc as the broadest factors.

There are several points to elaborate concerning what became known as Cattell's (1987) investment theory. First, as conceptualized by Cattell (1943, 1987; see also Ackerman, 1996; Hebb, 1942) the construct of Gc is quite different from that of Gf or any other cognitive ability. 
As framed by Cattell (1987), Gc is the product of Gf and other cognitive and non-cognitive processes - it is not a cognitive ability in its own right; it is simply the information one has amassed throughout life (cf. Horn \& McArdle, 2007). It does, however, act as a cognitive ability in that (1) individuals differ in the amount of information they have accumulated, (2) these individual differences are fairly stable, and (3) what one currently knows facilitates performance on other tasks (Beier \& Ackerman, 2005; Ericsson \& Kintsch, 1995; Gustafsson \& Undheim, 1992; Hambrick, 2003; Larsen, Hartmann, \& Nyborg, 2008; Moehring, Schroeders, \& Wilhelm, 2018).

Second, according to this theory, the investment of Gf into various activities that impart knowledge entwines Gf and Gc in a causal relationship (cf. Ferrer \& McArdle, 2004). Consequently, one can extract a higher-order intelligence factor, however, this factor is not $g$ but another manifestation of Gf. Cattell labeled this higher-order factor historical $G f$ to indicate that the action of Gf in the past was partly responsible for present Gc and is, of course, intimately related to current Gf. Indeed, researchers have found that Gf assessed at an earlier point in time continues to influence Gc development later in life (Thorsen et al., 2014). Moreover, Gf and $g$ are often perfectly or nearly perfectly correlated (e.g., Gustafsson, 1984), particularly in homogenous samples where the role of the environment is minimized and a greater proportion of variance in Gc is due to Gf (Valentin Kvist \& Gustafsson, 2008).

Finally, Cattell (1987) pointed out that because the development of Gc is partly driven by available opportunities, interests, and other non-cognitive factors, Gc can take many forms. This poses somewhat of a problem for the measurement of Gc, as individuals may be equally knowledgeable but differ in knowledge about specific topics (e.g., sports, politics, intelligence research). To account for the protean nature of Gc, in children and young adults, Gc is often 
measured via linguistic abilities (e.g., reading comprehension) or by assessing topics encountered in school - material that all members of a particular population are expected to have encountered.

Although the present study was not specifically designed to test Cattell's theory of Gf and Gc, it did guide the study. For opposing view points and/or contradictory evidence, concerning Cattell's theory of Gf and Gc, see Horn and McArdle (2007) and Ferrer and McArdle (2004).

\section{Immediate and Long Term Memory}

Immediate memory (STM and/or WM; see below) refers to a cognitive system that maintains a small amount of information in mind. In contrast, LTM refers to a system involved in storing a seemingly limitless amount of relatively permanent information (Cowan, 2008; Shiffrin \& Atkinson, 1969).

Currently, several prominent theories advance a multicomponent view of memory in which immediate memory and LTM are considered distinct but related constructs (e.g., Cowan, 1999; Oberauer, 2002; Shipstead et al., 2014; Unsworth \& Engle, 2007a). As evidence for their distinctiveness, researchers cite behavioral and neuropsychological evidence (Baddeley, 1970; Baddeley \& Dale, 1966; Basso, Spinnler, Vallar, \& Zanobio, 1982; Glanzer \& Cunitz, 1966; Majerus, Norris, \& Patterson, 2007; Papagno \& Vallar, 1995; Scoville \& Milner, 1957; Warrington \& Shallice, 1969) indicating that immediate and long-term memory are differentially affected by various manipulations (e.g., semantic and perceptual similarity; Baddeley, 1966) and appear to rely on different brain regions (Jeneson \& Squire, 2012). Though these memory factors are distinguishable, in neurotypical individuals, immediate memory and LTM have a reciprocal relationship, with immediate memory performance being supported by LTM processes (Botvinick, 2005; Gathercole, 1995; Hulme, Maughan, \& Brown, 1991; Majerus, Martinez 
Perez, \& Oberauer, 2012; Schweickert, 1993; Woodward, Macken, \& Jones, 2008) and LTM performance being supported by immediate memory processes (Baddeley, Gathercole, \& Papagno, 1998; Gupta \& Tisdale, 2009). Moreover, LTM and immediate memory tasks capture other, more general abilities — such as attention control (Shipstead et al., 2014; Unsworth, 2019) — and this increases the magnitude of observed relationships. Thus in investigating one memory system or factor, it is important to also consider the other, as there is significant overlap in brain regions and cognitive processes.

Immediate memory ${ }^{1}$. Two terms often used to refer to immediate memory are STM and WM. These terms are occasionally used interchangeably or with one or the other term being used as a superordinate term (e.g., Colom, Shih, Flores-Mendoza, \& Quiroga, 2006; Cowan, 2008; Cowan, 2017; Engle, Tuholski, Laughlin, \& Conway, 1999; Oberauer et al., 2018). As elaborated below, here immediate memory is conceptualized similarly to the multicomponent model of WM that includes a central executive and multiple domain-specific components (Baddeley, 2012; Baddeley \& Hitch, 1974).

Both STM span and WM capacity (WMC) are considered immediate memory abilities and, appropriately, both are operationalized similarly. For example, a common STM paradigm is the simple span, in which individuals are asked to recall a small set of items (i.e., less than nine) in the order presented immediately after presentation. A common WM paradigm is the complex span, in which individuals are asked to recall a small set of items that, at presentation, are interleaved with a processing task (Daneman \& Carpenter, 1980). As in simple span tasks,

${ }^{1}$ The term primary memory is occasionally used to refer to immediate memory however there are subtle differences in the way the term is used among researchers (e.g., James, 1890; Shipstead et al., 2014). 
participants are to recall the memoranda in the order presented and recall begins immediately after presentation.

Superficially, the obvious difference between the two paradigms is that the WM version includes a processing component while the STM version does not. It is posited, however, that this difference results in WMC tasks being more reliable indicators of a domain general ability to maintain attention (Engle, 2002, 2018; Engle et al., 1999). According to one account, the processing component in a complex span task disrupts domain- and task-specific mnemonic strategies, such as rehearsal (Cowan, 2008; La Pointe \& Engle, 1990; Reisberg, Rappaport, \& O'Shaughnessy, 1984; cf., Bayliss et al., 2005). When mnemonic strategies are curtailed, the onus falls on attention control processes to maintain and retrieve memory representations (Cowan, 2008; Engle et al., 1999; La Pointe \& Engle, 1990; Unsworth \& Engle, 2006, 2007a). Other studies, however, have pointed out that while strategy use may be hampered, it is not eliminated, and strategy use does account for individual differences in WMC performance (e.g., Bailey, Dunlosky, \& Kane, 2008; Dunlosky \& Kane, 2007). According to an alternative account, the processing component increases interference (Oberauer, Lewandowsky, Farrell, Jarrold, \& Greaves, 2012) and this results in increased demand on attention control to maintain attention on relevant information.

Thus, regardless of the account one favors, complex span tasks are purported to be more reliable measures of a domain-general ability to maintain relevant information in mind while 
STM span tasks reflect domain-specific processes to a greater degree (Kane et al., 2004) ${ }^{2}$. Implicit in this description is that there is one WM system but several STM systems (e.g., visuospatial, auditory-verbal, etc.). However, because WMC reflects a domain-general ability to maintain information in mind, it is implicated in all immediate memory tasks and therefore can be seen as the broader immediate memory ability (for a similar argument, see Engle et al., 1999).

Long-term memory. With regard to LTM, the present study is primarily concerned with declarative $\mathrm{LTM}^{3}$ as opposed to non-declarative LTM (for a review, see Squire, Knowlton, \& Musen, 1993); however, LTM (without specifying declarative or non-declarative) is used whenever non-declarative LTM processes may also be relevant.

Individual differences in dLTM ability are indexed by tasks that assess recall or recognition of more information than can be maintained in immediate memory. Examples of dLTM paradigms include paired-associate learning and free recall.

${ }^{2}$ Note, though the discussion is focused on complex span tasks, other putative measures of WMC do exist (e.g., visual arrays, running span, and n-back tasks; Shipstead et al., 2014; Wilhelm et al., 2013), and these also tend to hinder rehearsal strategies and/or there is evidence that interference partially accounts for their relationship with Gf (e.g., Harrison, 2017; Shipstead \& Engle, 2013).

${ }^{3}$ Another term commonly used in the literature to refer to declarative LTM is secondary memory (James, 1890; Unsworth \& Engle, 2006; Waugh \& Norman, 1965). 


\section{Memory and Fluid Intelligence}

Immediate memory and Gf. Of the two immediate memory factors, it is WMC that is the more robust predictor of Gf performance (Conway, Cowan, Bunting, Therriault, \& Minkoff, 2002; Engle et al., 1999; Kane et al., 2004; cf., Ackerman et al., 2005).

According to the executive attention account, the relationship between Gf and WMC is primarily due to the increased demand that WMC tasks place on attention control (Engle, 2002; Shipstead, Harrison, \& Engle, 2016). Gf tasks consists of complex and resource demanding problems; individuals who are better able to maintain attention on the task at hand have easy access to accurate memory representations that can be manipulated and built upon to form more complex representations (see also Oberauer, Süß, Wilhelm, \& Sander, 2007)..

Another relevant (and related) theory is the dual-component model (Unsworth \& Engle, 2006, 2007a). According to the dual-component model, in addition to the ability to sustain attention, immediate memory tasks, particularly WMC tasks, also place great demands on LTM storage and retrieval (Unsworth \& Engle, 2006). The increased reliance on LTM is due to the fact that, in disrupting mnemonic strategies and/or increasing interference, memoranda in WMC tasks are more likely to be displaced from immediate memory and must be retrieved from LTM. This contribution from LTM processes adds to the predictive power of WMC tasks because it is likely that while attempting to solve a Gf problem, at least some information that is critical to solving the Gf item will be displaced from immediate memory and need to be retrieved from LTM - thus at least some portion of the variance in Gf performance captured by WMC tasks is due to individual differences in LTM ability.

Long-term memory. As noted above, at least one theory implicates LTM processes in the relationship between WMC and Gf but there is conflicting evidence. Some have reported 
that, indeed, dLTM ability, assessed by associative learning tasks and the like, accounts for a significant proportion of variance in Gf performance above and beyond WMC (e.g., Kaufman, DeYoung, Gray, Brown, \& Mackintosh, 2009; Mogle, Lovett, Stawski, \& Sliwinski, 2008; Unsworth, Brewer, \& Spillers, 2009), while others have failed to find such effects (e.g., Shelton, Elliott, Matthews, Hill, \& Gouvier, 2010; Unsworth \& Spillers, 2010; Wilhelm et al., 2013).

It is possible that tasks of dLTM ability may account for additional variance in Gf performance over and above WMC because they are more reliable indicators of LTM processes needed to solve Gf tasks, such as LTM retrieval (Unsworth \& Engle, 2006, 2007a) and online learning (Carpenter, Just, \& Shell, 1990; Harrison, Shipstead, \& Engle, 2015; Ren, Wang, Altmeyer, \& Schweizer, 2014). However, As Wilhelm et al. (2013) point out, it is possible that the relationship between $\mathrm{ALTM}$ ability and Gf may be due to WMC. If WMC allows one to maintain and manipulate information, then WMC should be critical to dLTM ability as well, as deeper processing supports learning (Craik \& Lockhart, 1972; Craik \& Watkins, 1973; Kyllonen, Tirre, \& Christal, 1991).

\section{Memory and Crystallized Intelligence}

Immediate memory and Gc. There are reasons to expect that one or more memory factors directly support Gc. As noted above, WMC likely supports information processing and this in turn supports the acquisition of knowledge and therefore Gc. Indeed, some have reported moderate correlations between WMC and Gc tasks (Daneman \& Merikle, 1996; Dang et al., 2012; Haavisto \& Lehto, 2005). Still, there is evidence that WMC is, at best, only weakly related to Gc (Colom, Rebollo, et al., 2006; Dang et al., 2014; Unsworth, 2010). This may be because a large proportion of our knowledge is acquired implicitly (i.e., without attention) or incidentally 
(i.e., when attention is directed towards another goal) and therefore the effect of WMC on the development of Gc may, in fact, be quite modest.

Given that WMC and STM are highly related, it is likely that STM is related to Gc for the same reasons as WMC, however, processes specific to auditory-verbal STM likely explain individual differences in Gc over and above WMC. A great deal of our declarative knowledge is obtained via verbal processes (e.g., reading) and, accordingly, Gc is often assessed via languagebased tasks (Carroll, 1993). As such, there is overlap in the processes assessed by auditoryverbal STM and Gc tasks and, in fact, auditory-verbal STM tasks do tend to be excellent predictors of verbal ability and language learning (Baddeley et al., 1998; Martin \& Ellis, 2012; Verhagen \& Leseman, 2016). In contrast, there is little theoretical basis for anything more than a modest association between non-verbal measures of STM span and Gc when auditory-verbal span and WMC is held constant.

Declarative long-term memory and Gc. As defined above, dLTM ability relates to processes involved in storing information in some relatively permanent form and Gc was defined as the network of knowledge one possesses—-thus, dLTM ability should directly influence Gc.

\section{The Present Study}

The present study utilized data from a study investigating predictors of lexical learning in signed and spoken language amongst hearing non-signing adults (Martinez \& Singleton, 2019). The dataset included measures of Gf, Gc, associative learning of signs and words (indexing dLTM ability), auditory-verbal span, STM span for signs (termed movement span here ${ }^{4}$ ), a

\footnotetext{
${ }^{4}$ Research suggests that non-signers initially process signs as human body movements (e.g., Newman-Norlund, Frey, Petitto, \& Grafton, 2006; J. T. Williams, Darcy, \& Newman, 2016), thus in this study, with this particular population, STM for signs is considered non-verbal.
} 
demographic questionnaire, and the OSIQ (Blajenkova, Kozhevnikov, \& Motes, 2006), an imagery questionnaire that is irrelevant to the present study.

\section{Method}

Participants. Participants were recruited from the School of Psychology research participant pool and surrounding community. Participants recruited from the participant pool were compensated for their time with course credit and an additional $\$ 15$ for completing the study. Community participants received up to $\$ 65$. The local Institutional Review Board approved this study and informed consent was always obtained prior to participation.

Individuals could participate in the study if they were between the ages of $17-35$, were fluent in English, had resided in the USA at least since the age of five, and had normal or corrected-to-normal hearing and vision. Participants were excluded if they indicated fluency in ASL or Turkish (languages used in two of the tasks), were diagnosed with a language disorder, or if they possessed an upper-body movement disorder affecting the use of their arms or hands.

A total of 286 individuals elected to participate in this study, however, due to attrition (34 individuals), failure to follow instructions (3 individuals), or failure to meet the inclusion/exclusion criteria (13 individuals), only data from 236 individuals were analyzed.

Procedure. Participants completed 25 cognitive tasks and two questionnaires over two sessions however, only data from 25 of the tasks are used here. The first session lasted approximately 2.5 hours and the second lasted approximately 2 hours. Nearly all tasks were completed on PCs running E-Prime 3.0 (W. Schneider, Eschman, \& Zuccolotto, 2002). Task administration order was fixed, with all span and dLTM ability tasks administered during the 
first session and the questionnaires, WMC, and intelligence tasks administered during the second session (for administration order, see Table 1 below).

\section{Tasks}

All tasks developed in-house are available online at https://osf.io/xmype/. Descriptions of the tasks used in this study follow.

Crystallized Intelligence. Gc was assessed via four tests. In the Reading (comprehension) test, participants had up to 20 min to answer 17 multiple-choice questions pertaining to 5 short passages drawn from released SAT and GRE tests. Verbal knowledge was assessed via the Extended Range Vocabulary (Vocab) test (Ekstrom, French, Harman, \& Dermen, 1976) which consisted of two parts, each with a 6 min time limit and 24 multiple-choice questions in which participants had to match a given word with a synonym or near-synonym. Knowledge of English grammar and usage was assessed via the Gram test, which consisted of 21 “improving sentences” items from official SAT practice tests released between 2004 and 2013. Participants read sentences and had to decide whether the sentence could be improved by substituting one portion of the sentence with one of four alternatives. Participants were given up to $10 \mathrm{~min}$ to complete this task. The last Gc task, Information (Info), assessed general knowledge. In part 1 of the task, participants had 7 min to complete the Information subscale from the Multidimensional Aptitude Battery II (Jackson, 1998), which consists of 40 multiplechoice questions. In part 2, participants completed an additional 11 items that were developed inhouse and were intended to broaden the domains of knowledge assessed. Participants had up to 2 min to complete part 2.

Fluid Intelligence. Gf was assessed via three inductive reasoning tasks and a test of general visual processing. Raven's advanced progressive matrices (Ravens; Raven, Raven, \& 
Court, 1998) is a figural inductive reasoning task. Participants were given 10 minutes to answer 18 items from set II. The spatial learning ability test (SLAT; Embretson, 1992) presents participants with a representation of an unfolded cube with simple figures on each of the six faces alongside four two-dimensional representations of intact cubes (see Figure 1). The participant is to select the intact cube that matches the target when mentally folded and, if appropriate, rotated. Although the SLAT is better thought of as a visual processing task, such tasks tend to load heavily on Gf (Lohman, 1996; Marshalek, Lohman, \& Snow, 1983). Participants were allowed 15 min to attempt 20 items. The third Gf task was letter sets (LetSets; Ekstrom et al., 1976). Participants had 7 min to complete 30 items. Each item consisted of five sets of letters (e.g., ABCD, GHIJ, MNOP, STUV, ZYXW) — the participant was to identify the set that did not obey the same rule as the others (e.g., ZYXW in the example above). The fourth Gf task was number series (NumSeries; Thurstone, 1938). Participants were to choose which of five answer choices best completed a sequence of numbers (e.g., 1,1,2,3,5,8 ...). There were 15 items and participants had up to 5 min to complete them.
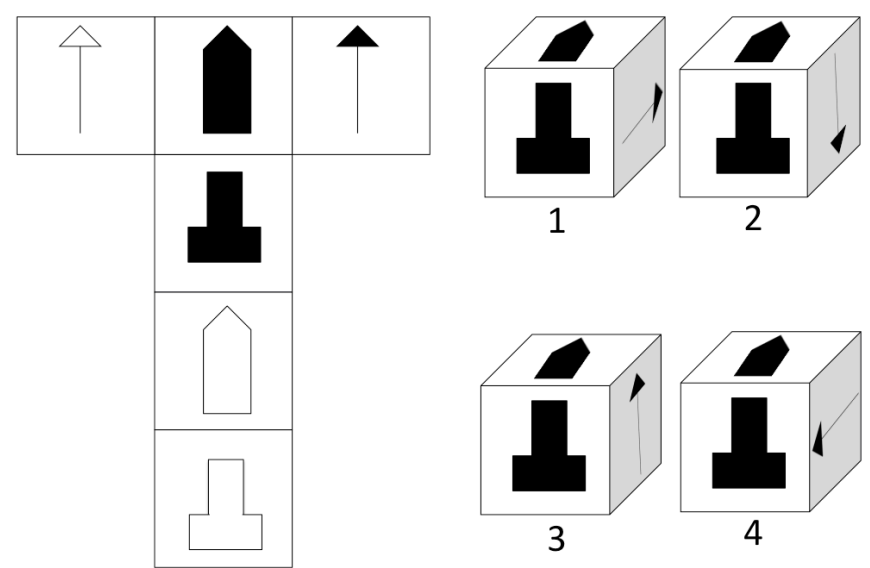

Figure 1. A sample SLAT item. 
Short-term memory span. STM span was assessed via three auditory-verbal tasks and three movement tasks. Within each domain, there were two classes of tasks: serial recall and discrimination (same-different) tasks. In a serial recall task, participants viewed a set of stimuli and were to recall the set in the same order as it had been presented. Serial recall tasks were all scored using partial credit unit scoring, such that, participants received a fraction of a point for every item correctly recalled in its ordinal position (see Conway et al., 2005, pp. 775-777). In discrimination tasks, a target item or set of items is presented followed by a reproduction that is either exactly the same or differs from the target in some aspect; the participant is to judge whether the reproduction is in fact the same or different. A single point was awarded for every correct trial.

Auditory-verbal short-term memory span. The three auditory-verbal span tasks were letter span (LetSpan), nonword recognition (NWRec), and nonword span (NWSpan). In the LetSpan, participants attempted to recall four to nine letters. There were three trials at each set length and all letters were simultaneously presented on screen for a length of time equal to 500 ms per letter. The NWRec task is a discrimination task similar to the nonword recognition task used by Gathercole, Pickering, Hall, and Peaker (2001). In this version, participants heard (via headphones) three to five monosyllabic pseudowords and judged whether reproductions were the same of different. If they were the same, then the exact same audio file was replayed; if they were different, then a pair of adjacent pseudowords had been transposed. There were a total of 36 trials. In the final auditory-verbal STM task, the NWSpan, participants heard a series of two to six monosyllabic pseudowords and attempted to recall them in the same order. There were three trials at each set length for a total of 15 trials. 
Movement short-term memory span. The three movement span tasks were the nonsign paired discrimination task (NSPT), probed sign (ProSign) task, and sign configuration (SignCon) task. The NSPT used here is a shortened version of the NSPT used by Martinez and Singleton (2018). Participants see a film clip of a target sign produced by one individual followed by a reproduction produced by a different individual. The objective is to judge whether the signs are the same or different. If they are different, then the signs differ in the handshape used, the orientation of the hand, or the movements made by the fingers, wrist, or shoulder. There were two blocks of 28 trials. The same target video files were used across the two blocks, however, reproductions were made by two different individuals (see Figure 2).

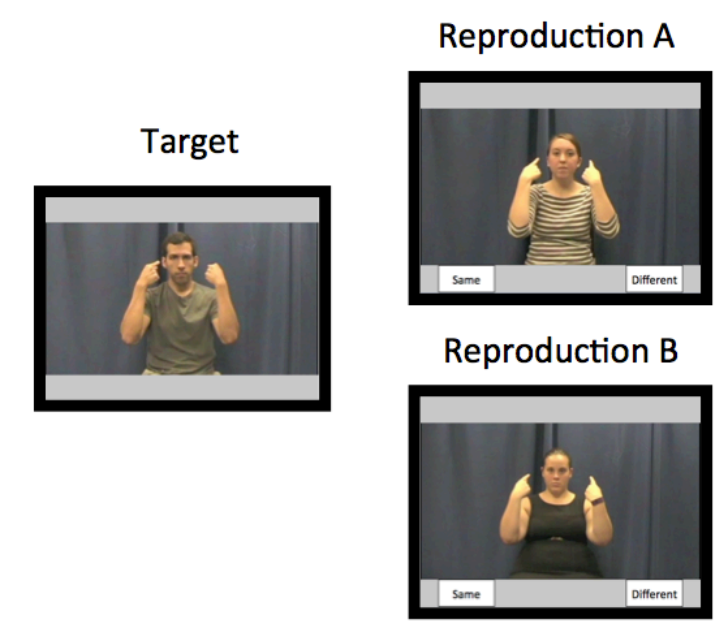

Figure 2. Two items from the NSPT. The target is used twice, while the reproductions differ across blocks. Note: only the final positions are shown here.

The ProSign task was similar to the NSPT, however, in this task participants first saw a set of three to six pseudosigns followed by a cue and then a single probe. The probe was either exactly the same as one of the pseudosigns in the set or it differed by handshape, orientation, or movement (as with the NSPT). There were 10 trials at each set length for a total of 40 trials. 
The third movement STM task is the SignCon. The SignCon is a dual-task in which participants completed two span tasks: a letter span and a pseudosign span (Figure 3). The critical portion of the task was the pseudosign portion - the letter span portion was simply intended to disrupt verbal mediation (e.g., labeling).

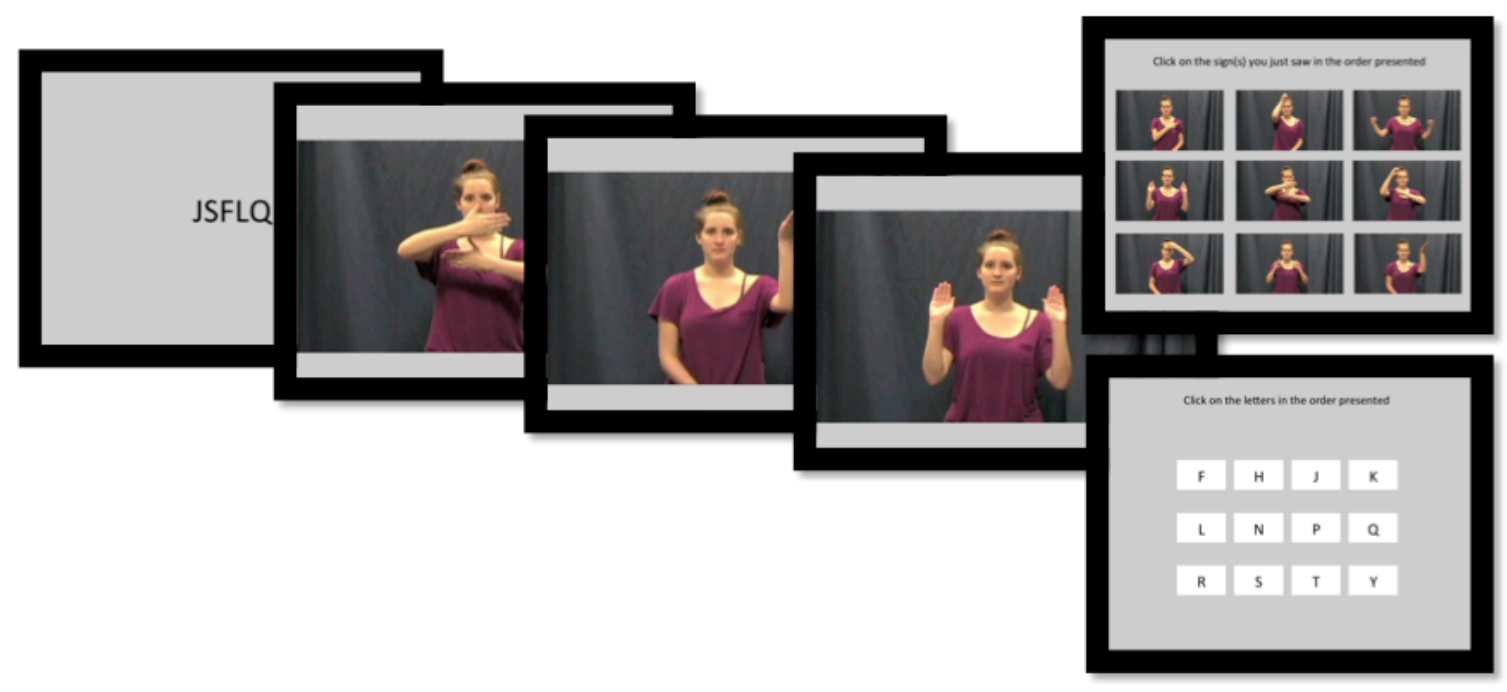

Figure 3. The SignCon. Participants always saw a set of letters followed by 3-6 pseudosigns. Next, their memory for the letters or the pseudosigns is tested.

Each trial of the SignCon began with the letter span portion. The length of the set of letters was always equal to one minus the maximum number of letters that a participant was able to perfectly recall over three trials in the LetSpan task administered earlier in the session. In this way, the memory load should have been functionally equivalent across participants. Participants were told to verbally rehearse the letters during the second portion of the task, the pseudosign span.

The pseudosign portion consisted of one to four video files depicting pseudosigns; the pseudosigns differed from each other in at least two features and were therefore visually distinct. Next, participants were either tested on the set of letters or the set of pseudosigns. If they were tested on the set of letters, then they saw a screen with the entire pool of letters and clicked on 
the letters in the order they presented. If they were tested on the pseudosigns, then they saw a screen with static images of the entire pool of signs — one static image representing a key configuration for every sign. Participants were to click on the images in the order they were presented.

There were a total of 20 trials. To ensure compliance, eight trials tested memory for letters while 12 trials assessed memory for the pseudosigns. Because the critical trials were the pseudosign trials, the maximum possible score was 12 .

Working memory capacity. WMC was assessed with three shortened complex span tasks (Foster et al., 2015). Like the STM span tasks, all complex span tasks were scored using partial credit scoring.

In the operation span (Ospan), the memory component required recall of letters while the processing component required the verification of simple math equations. In symmetry span (SymSpan), the to-be-remembered items were locations in a $4 \times 4$ matrix while the secondary task was to judge whether a figure was symmetrical along its vertical axis. The final WMC task was the rotation span (RoSpan). Here participants attempted to memorize a sequence of arrows varying in size and direction while also judging whether rotated letters were mirrored or not.

dLTM ability. The ability to retain information over the long-term was assessed via associative learning. All dLTM ability tasks were designed in-house but modeled after other associative learning tasks (Kaufman et al., 2009; Tamez, Myerson, \& Hale, 2008; Underwood, Boruch, \& Malmi, 1978; B. A. Williams \& Pearlberg, 2006). Participants completed four word learning tasks in which they attempted to learn the meaning of unknown words associated with novel words and four sign learning tasks in which they learned signs and their associated English words. In each case, an unfamiliar lexical item was paired with one or more short (1-3 syllable), 
familiar, concrete English noun(s). Unfamiliar lexical items were either drawn from natural languages that were unfamiliar and unrelated to any languages the participants knew or they were contrived (i.e., pseudosigns and pseudowords).

Practice trials were always provided and, importantly, participants were instructed to use an elaborative rehearsal strategy and examples were provided. This was done to minimize differences in strategy use that became apparent during pilot testing.

Except where noted, all items were restudied and retested regardless of prior performance within a task unless a perfect score was achieved — in that case, the task was automatically terminated. Scores were calculated as the sum of performance across test blocks; when a participant achieved a perfect score on a particular test block, the maximum number of points was given for it and any remaining blocks. Note, for some tasks, the total number of blocks administered differs from the number of blocks used to calculate scores. This was done when a majority of participants achieved perfect scores in earlier blocks and thus variability decreased while skew increased.

In the American Sign Language (ASL) sign learning (ASL-SL) task, participants attempted to learn 24 ASL-English pairs over a maximum of two trials (see Figure 4). All signs were selected from the ASL-LEX database (Caselli, Sehyr, Cohen-Goldberg, \& Emmorey, 2016) and effort was made to ensure that the signs were visually distinct and low in iconicity, such that a sign-naïve individual would be unable to guess the meaning of a sign. It should be noted that although sign iconicity was low, the ASL signs were not entirely arbitrary; hence, compared to other lexical learning tasks, a larger number of items and a lower number of study-test blocks were needed to achieve appropriate task difficulty. 


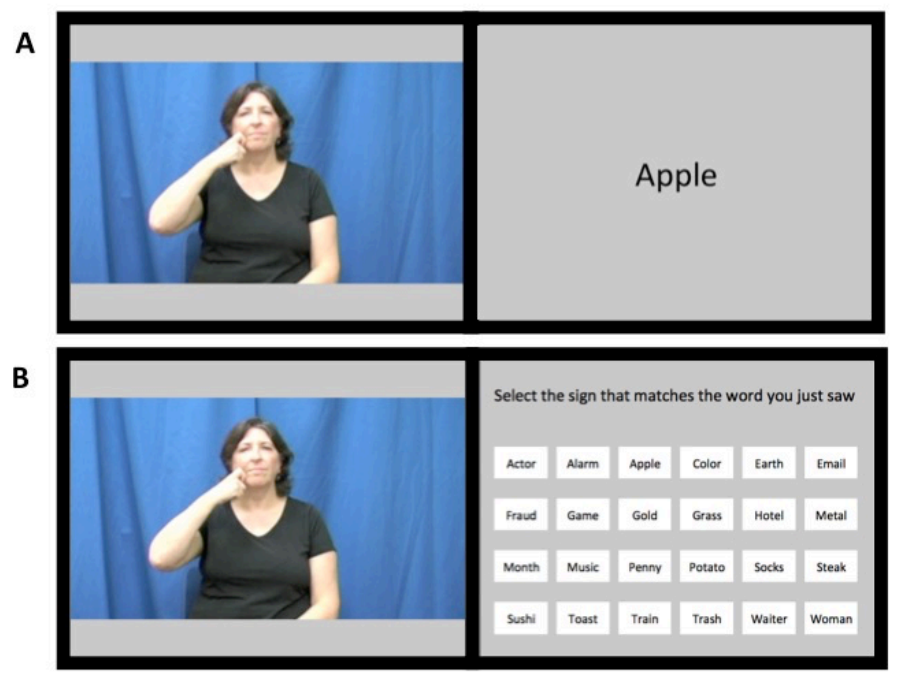

Figure 4. A single item from the ASL-SL. Panel A: during the learning portion, the ASL sign APPLE is shown immediately followed by the written form. Panel B: during testing, the ASL sign APPLE is shown and is immediately followed by the response screen-participants are to click the correct choice.

In the pseudosign learning (PSL) task, participants attempted to learn 15 pseudosignEnglish pairs over a maximum of three trials. Here, a drop-out procedure was used such that once a participant correctly recalled an item, it was dropped from subsequent study and test blocks. This was done to control for degree of overlearning, which supports long-term retention (Driskell, Willis, \& Copper, 1992). Had a drop-out procedure not been used, the fastest learners would have been advantaged on the delayed pseudosign learning (DPSL) task.

The DPSL consisted of a single test block from the PSL, administered after a filled interval of approximately $30 \mathrm{~min}$. To control for initial learning, scores on the DPSL were calculated as a percentage of the total number of items that had been learned in the PSL over four blocks.

The final sign learning measure, the three-term sign learning (3TSL) task is a complex associative learning task modeled after the three-term contingency learning task (B. A. Williams \& Pearlberg, 2006). In the 3TSL, participants attempt to learn six pseudosigns, each paired with 
a sequence of three English words. At test, participants see a pseudosign and number and must recall the word that was associated with that sign and that sequence position (Figure 5).

\section{A}

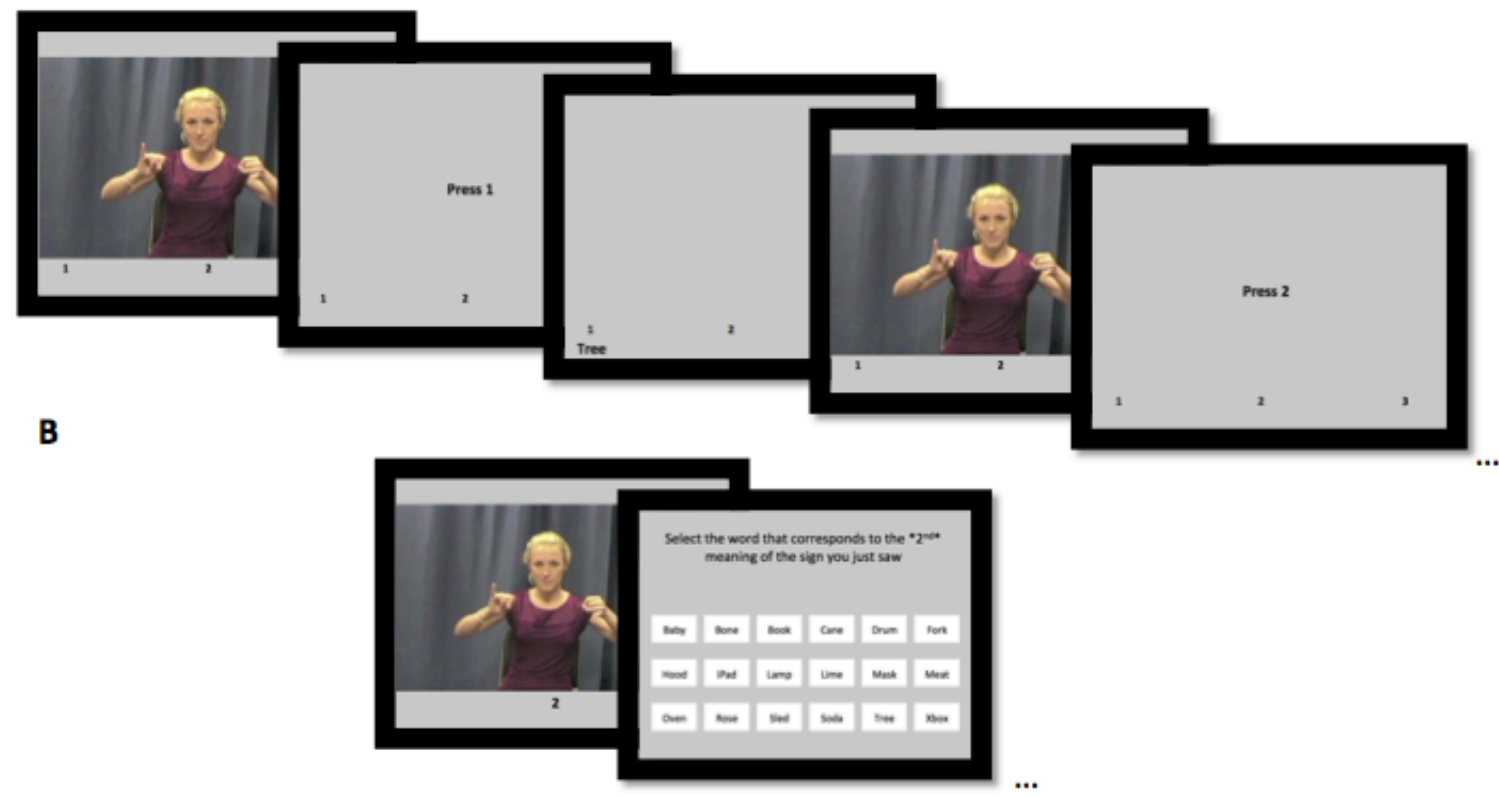

Figure 5. An item from the 3TSL. Panel A shows a portion of the study block while panel B shows an item at test.

The word learning tasks were very similar to the sign learning tasks, however, unfamiliar lexical items were delivered through headphones. In the Turkish word learning (TWL) task, participants attempted to learn 15 Turkish-English pairs over a maximum of three blocks. In the pseudoword learning (PWL) task, participants attempted to learn 15 pseudoword-English pairs over a maximum of 3 blocks and a drop-out procedure was employed. The delayed pseudoword learning (DPWL) task was administered approximately 40 min after the PWL; it consisted of one test block of PWL items. Scores were calculated as the ratio of items correctly recalled in the DPWL over the total number of pairs learned in the PWL over six trials. The fourth word learning task was the three-term word learning (3TWL) task. Here, participants attempted to 
learn six pseudowords and their associated number cues and English words. Scores were calculated as the total number correct over three trials.

\section{Statistical Analyses}

Data preparation. Data was converted from raw scores to percentages then screened for outliers and missing values. Eleven values were deemed outliers—defined as values 3.5 standard deviations or greater from the mean—and 61 values were deemed missing at random.

Statistical procedure. All structural equation models were created using the Lavaan package (Rosseel, 2012) for R (R Core Development Team, 2013). Missing values dealt with by using full information maximum likelihood and parameters were tested using t-tests- $-\mathrm{p}$-values less than .05 were considered significant.

Model fit was assessed using several recommended statistics (Kline, 2016): model chisquare, comparative fit index (CFI), standardized root mean square residual (SRMR), and root mean square error of approximation (RMSEA). Significant chi-square values are indicative of poor fit, however, because of the moderately large sample size used here, the chi-square test tends to be overly sensitive. CFI is considered a goodness-of-fit statistic, ranging in value between zero and one - values equal or greater than .95 are considered good. SRMR and RMSEA are so called badness-of-fit statistics- they also range between zero and one but lower values are indicative of good fit, with SRMR values below .08 and RMSEA values near .05 considered good.

\section{Results}

Data and analysis files can be found at https://osf.io/xmype/. Of the final sample, 234 individuals answered a demographic questionnaire. The mean age was 21.24 years $(\mathrm{SD}=3.57)$; approximately $63 \%$ of participants identified as female; and nearly all (94.4\%) indicated that 
they were currently postsecondary students or had attended a postsecondary school. Just over half of participants $(52.3 \%)$ participated for course credit while the rest were community members (including students from local colleges and universities) and were compensated with up to $\$ 65$.

Descriptive statistics and internal consistency coefficients (including McDonald's omega; McDonald, 1999) are provided in Table 1. Of note is the fact that four tasks (NSPT, proSign, symSpan, and roSpan) had rather low internal consistency values (below .70), raising some concern about their reliability. Importantly, however, an inspection of the bivariate correlations (Table 2) revealed strong within-construct relations (e.g., the symSpan correlates strongly with the other two WMC measures, oSpan and roSpan). Thus measurement error was sufficiently low enough to allow for appropriately strong correlations.

\section{Latent Variable Analyses}

First, a confirmatory factor analysis was conducted with auditory-verbal span, movement span, WMC, dLTM ability, Gc, and Gf as factors. For theoretical and practical reasons (namely, to mitigate the effects of multicollinearity), the WMC factor was estimated as the variance that is common among all of the immediate memory factors and is, therefore, considered a domaingeneral immediate memory factor. The STM factors represent the variance that is unique to auditory-verbal span or movement span when variance in common with WMC is partialled out; therefore, these factors are should be more domain-specific. To remind the reader that the STM factors have been residualized, the subscript "res" has been affixed to the STM factors. dLTM ability was modeled hierarchically, with the sign and word learning factors as lower-order variables. Finally, Gc and Gf were modeled as independent but correlated factors. 
Table 1. Descriptive statistics and reliabilities

\begin{tabular}{lllrlrrrrr}
\hline Order & Construct & Task & Max & Mean & Range & Skew & Kurtosis & $\boldsymbol{\alpha}$ & $\boldsymbol{\omega}$ \\
\hline $2-1$ & & Reading & 17 & $.50(.22)$ & $.00-1.00$ & .00 & -.59 & .78 & .79 \\
$2-3$ & \multirow{2}{*}{ Gc } & Vocab & 48 & $.53(.15)$ & $.15-.85$ & -.03 & -.41 & .84 & .84 \\
$2-4$ & & Gram & 21 & $.45(.20)$ & $.00-.95$ & .15 & -.57 & .78 & .79 \\
$2-2$ & & Info & 51 & $.60(.13)$ & $.14-.90$ & -.86 & .97 & .84 & .85 \\
\hline $2-8$ & & Ravens & 18 & $.57(.21)$ & $.06-1.00$ & -.39 & -.40 & .81 & .81 \\
$2-11$ & \multirow{2}{*}{ Gf } & SLAT & 20 & $.55(.25)$ & $.00-.95$ & .10 & -1.18 & .88 & .88 \\
$2-10$ & & NumSeries & 15 & $.67(.20)$ & $.13-1.00$ & -.44 & -.63 & .78 & .79 \\
$2-9$ & & LetSets & 30 & $.57(.16)$ & $.17-.90$ & -.36 & -.45 & .84 & .85 \\
\hline $1-4$ & \multirow{2}{*}{ AV-Span } & LetSpan & 117 & $.81(.09)$ & $.49-1.00$ & -.67 & .43 & .78 & .78 \\
$1-5$ & NWRec & 36 & $.80(.12)$ & $.42-1.00$ & -.62 & -.13 & .78 & .78 \\
$1-6$ & & NWSpan & 60 & $.71(.11)$ & $.40-.99$ & -.18 & .05 & .76 & .76 \\
\hline $1-11$ & \multirow{3}{*}{ M-Span } & NSPT & 56 & $.80(.07)$ & $.57-.98$ & -.53 & .52 & .72 & .72 \\
$1-12$ & ProSign & 40 & $.67(.11)$ & $.40-.90$ & -.27 & -.31 & .67 & .68 \\
$1-13$ & & SignCon & 30 & $.61(.17)$ & $.06-.92$ & -.68 & .48 & .75 & .75 \\
\hline $2-5$ & \multirow{2}{*}{ WMC } & OSpan & 25 & $.82(.18)$ & $.14-1.00$ & -1.39 & 2.02 & .74 & .74 \\
$2-6$ & SymSpan & 14 & $.74(.23)$ & $.00-1.00$ & -1.00 & .83 & .68 & .68 \\
$2-7$ & & RoSpan & 14 & $.61(.23)$ & $.00-1.00$ & -.75 & .12 & .64 & .65 \\
\hline $1-1$ & & ASL-SL & 48 & $.71(.22)$ & $.08-1.00$ & -.96 & .27 & .93 & .93 \\
$1-2$ & & PSL & 45 & $.71(.20)$ & $.07-1.00$ & -.78 & -.05 & .87 & .87 \\
$1-3$ & & 3TSL & 54 & $.63(.27)$ & $.04-1.00$ & -.53 & -.78 & .95 & .95 \\
$1-7$ & \multirow{2}{*}{ dLTM } & DPSL & 15 & $.70(.22)$ & $.00-1.00$ & -.57 & -.04 & .83 & .83 \\
$1-8$ & ability & TWL & 45 & $.54(.24)$ & $.02-1.00$ & -.23 & -.90 & .91 & .91 \\
$1-9$ & & PWL & 45 & $.64(.25)$ & $.07-1.00$ & -.48 & -1.03 & .91 & .91 \\
$1-10$ & & 3TWL & 54 & $.49(.33)$ & $.00-1.00$ & .03 & -1.54 & .97 & .97 \\
$1-14$ & & DPWL & 15 & $.58(.25)$ & $.00-1.00$ & -.41 & -.45 & .83 & .83 \\
\hline
\end{tabular}

Note: Order = presentation order, with session followed by position-in-sequence; Max = maximum points possible in raw units; Mean and range are given as percentages; Gc = crystallized intelligence; $\mathrm{Gf}=$ fluid intelligence; AVSpan = auditory-verbal span; $\mathrm{M}$-Span = movement span; $\mathrm{WMC}=$ working memory capacity; $\mathrm{dLTM}=$ declarative LTM; Reading = test of reading comprehension; Vocab = extended range administration test; Gram = grammar and usage test; Info = information test; Ravens $=$ Raven's Advanced Progressive Matrices, Set II; SLAT = spatial learning ability test; NumSeries $=$ number series; LetSets $=$ letter sets; NSPT $=$ nonsign paired task; ProSign $=$ Probed Sign recognition task; SignCon = sign configuration task; OSpan = operation span; SymSpan $=$ symmetry span; RoSpan = rotation span; ASL-SL = ASL sign learning; PSL = pseudosign learning; $3 \mathrm{TSL}=$ three-term sign learning; DPSL = delayed pseudosign learning; LetSpan = letter span; NWRec $=$ Nonword Recognition; NWSpan = Nonword Span; TWL = Turkish word learning; $\mathrm{PWL}=$ pseudosign learning; $3 \mathrm{TWL}=$ three-term word learning; $\mathrm{DPWL}=$ delayed word learning 
Table 2. Zero-order correlations

\begin{tabular}{|c|c|c|c|c|c|c|c|c|c|c|c|c|c|c|c|c|c|c|c|c|c|c|c|c|c|}
\hline & 1 & 2 & 3 & 4 & 5 & 6 & 7 & 8 & 9 & 10 & 11 & 12 & 13 & 14 & 15 & 16 & 17 & 18 & 19 & 20 & 21 & 22 & 23 & 24 & 25 \\
\hline 1 Reading & 235 & 233 & 233 & 232 & 232 & 234 & 227 & 235 & 230 & 230 & 232 & 230 & 233 & 233 & 227 & 232 & 232 & 234 & 234 & 234 & 235 & 232 & 230 & 233 & 231 \\
\hline 2 Vocab & .61 & 234 & 234 & 231 & 231 & 233 & 226 & 234 & 229 & 229 & 231 & 229 & 232 & 232 & 226 & 231 & 231 & 233 & 233 & 233 & 234 & 231 & 229 & 232 & 230 \\
\hline 3 Gram & .58 & .62 & 234 & 231 & 231 & 233 & 226 & 234 & 229 & 229 & 231 & 229 & 232 & 232 & 226 & 231 & 231 & 233 & 233 & 233 & 234 & 231 & 229 & 232 & 230 \\
\hline 4 Info & .54 & .66 & .57 & 233 & 230 & 232 & 226 & 233 & 228 & 228 & 230 & 230 & 232 & 231 & 225 & 230 & 230 & 232 & 232 & 232 & 233 & 230 & 228 & 231 & 229 \\
\hline 5 ravens & .42 & .50 & .49 & .44 & 233 & 232 & 226 & 233 & 228 & 228 & 230 & 228 & 231 & 231 & 225 & 231 & 230 & 232 & 232 & 232 & 233 & 231 & 229 & 232 & 230 \\
\hline 6 slat & .41 & .49 & .44 & .45 & .63 & 235 & 227 & 235 & 230 & 230 & 232 & 230 & 233 & 234 & 227 & 232 & 232 & 234 & 234 & 234 & 235 & 232 & 230 & 233 & 231 \\
\hline 7 numSeries & .45 & .48 & .50 & .53 & .60 & .58 & 228 & 228 & 224 & 224 & 226 & 225 & 227 & 226 & 221 & 226 & 225 & 228 & 227 & 227 & 228 & 226 & 225 & 227 & 226 \\
\hline 8 letSets & .39 & .42 & .54 & .41 & .55 & .54 & .64 & 236 & 231 & 231 & 233 & 231 & 234 & 234 & 228 & 233 & 233 & 235 & 235 & 235 & 236 & 233 & 231 & 234 & 232 \\
\hline 9 letSpan & .35 & .32 & .43 & .30 & .26 & .26 & .40 & .40 & 231 & 231 & 228 & 227 & 229 & 229 & 223 & 228 & 229 & 230 & 230 & 230 & 231 & 228 & 226 & 229 & 227 \\
\hline 10 NWRec & .44 & .39 & .49 & .30 & .41 & .38 & .41 & .44 & .54 & 231 & 228 & 227 & 229 & 229 & 223 & 228 & 229 & 230 & 230 & 230 & 231 & 228 & 226 & 229 & 227 \\
\hline 11 Nwspan & .35 & .40 & .39 & .34 & .42 & .39 & .41 & .37 & .55 & .60 & 233 & 228 & 231 & 231 & 225 & 230 & 230 & 232 & 232 & 232 & 233 & 230 & 228 & 232 & 229 \\
\hline $12 \mathrm{NSPT}$ & .50 & .49 & .43 & .42 & .51 & .47 & .42 & .40 & .35 & .39 & .44 & 231 & 230 & 229 & 223 & 228 & 228 & 230 & 230 & 230 & 231 & 228 & 226 & 229 & 227 \\
\hline 13 proSign & .41 & .43 & .40 & .30 & .48 & .45 & .37 & .40 & .33 & .47 & .45 & .60 & 234 & 232 & 226 & 231 & 231 & 233 & 233 & 233 & 234 & 231 & 229 & 232 & 230 \\
\hline 14 signCon & .33 & .38 & .34 & .26 & .52 & .47 & .36 & .43 & .26 & .50 & .48 & .51 & .57 & 234 & 226 & 231 & 231 & 233 & 233 & 233 & 234 & 231 & 229 & 232 & 230 \\
\hline 15 Ospan & .32 & .27 & .34 & .27 & .34 & .34 & .44 & .38 & .38 & .39 & .46 & .37 & .30 & .29 & 228 & 225 & 225 & 227 & 227 & 227 & 228 & 225 & 223 & 226 & 225 \\
\hline 16 SymSpan & .30 & .27 & .39 & .27 & .49 & .45 & .48 & .39 & .34 & .33 & .32 & .42 & .36 & .37 & .40 & 233 & 230 & 232 & 232 & 232 & 233 & 231 & 229 & 232 & 230 \\
\hline 17 RoSpan & .27 & .20 & .29 & .30 & .40 & .32 & .44 & .31 & .28 & .27 & .31 & .31 & .31 & .36 & .37 & .53 & 233 & 232 & 232 & 232 & 233 & 230 & 228 & 231 & 229 \\
\hline $18 \mathrm{ASL}$ & .40 & .47 & .41 & .40 & .56 & .45 & .40 & .45 & .21 & .44 & .34 & .43 & .48 & .55 & .28 & .28 & .24 & 235 & 234 & 234 & 235 & 232 & 231 & 233 & 231 \\
\hline 19 PSL & .35 & .42 & .32 & .32 & .51 & .43 & .39 & .42 & .30 & .48 & .36 & .39 & .46 & .52 & .34 & .35 & .27 & .69 & 235 & 234 & 235 & 232 & 230 & 233 & 231 \\
\hline 20 TTSL & .42 & .46 & .42 & .40 & .61 & .51 & .51 & .50 & .35 & .52 & .46 & .51 & .51 & .58 & .33 & .37 & .37 & .72 & .70 & 235 & 235 & 232 & 230 & 233 & 231 \\
\hline 21 DPSL & .33 & .33 & .28 & .30 & .41 & .42 & .31 & .36 & .22 & .38 & .37 & .35 & .44 & .48 & .31 & .29 & .25 & .64 & .63 & .61 & 236 & 233 & 231 & 234 & 232 \\
\hline $22 \mathrm{TWL}$ & .44 & .55 & .50 & .39 & .55 & .44 & .49 & .50 & .41 & .59 & .58 & .41 & .49 & .52 & .36 & .38 & .32 & .62 & .66 & .71 & .51 & 233 & 229 & 232 & 230 \\
\hline $23 \mathrm{PWL}$ & .38 & .49 & .47 & .36 & .53 & .42 & .45 & .54 & .35 & .53 & .48 & .45 & .46 & .54 & .28 & .31 & .24 & .59 & .69 & .66 & .51 & .78 & 231 & 230 & 228 \\
\hline 24 TTWL & .38 & .47 & .45 & .34 & .54 & .46 & .45 & .46 & .38 & .55 & .52 & .47 & .46 & .57 & .35 & .38 & .35 & .57 & .65 & .75 & .50 & .77 & .74 & 234 & 231 \\
\hline 25 DPWL & .38 & .42 & .37 & .29 & .49 & .43 & .41 & .41 & .27 & .45 & .46 & .35 & .42 & .52 & .25 & .25 & .18 & .51 & .54 & .57 & .52 & .64 & .66 & .63 & 232 \\
\hline
\end{tabular}

Note: See Table 1 for key. Bivariate correlations are provided below the diagonal. Numbers on the diagonal (bold) represent the number of available data points for that particular variable; numbers above the diagonal indicate the sample size for the corresponding correlation. 
The confirmatory model fit the data well, $X^{2}(254)=419.02, \mathrm{p}<.000, \mathrm{CFI}=.954, \mathrm{SRMR}$ $=.046, \mathrm{RMSEA}=.052(90 \% \mathrm{CI}=.043, .061)$. The measurement model is depicted in Figure 6;

for correlations amongst the latent variables, see Table 3.

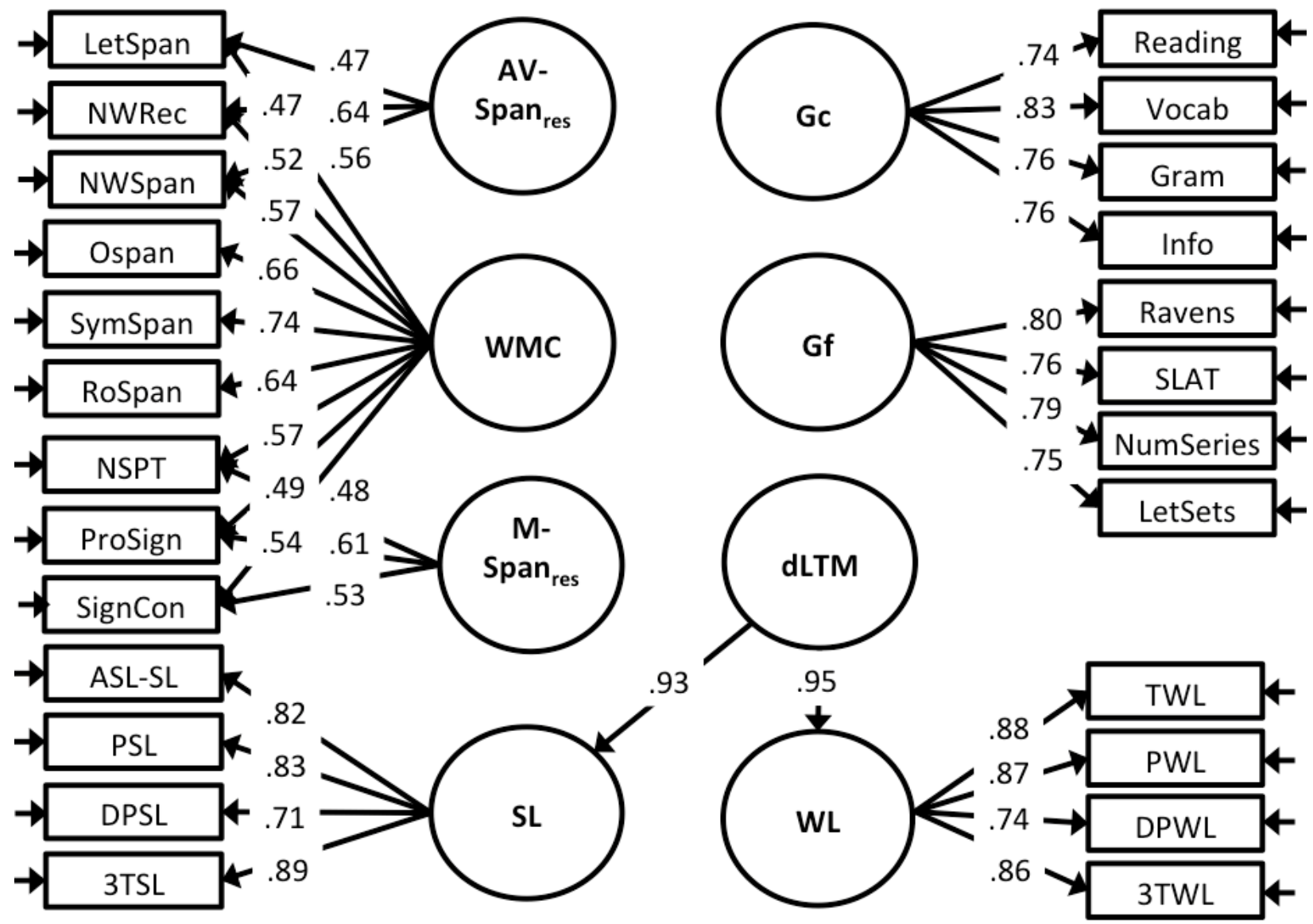

Figure 6. The measurement model. $\mathrm{Gc}=$ crystallized intelligence; $\mathrm{Gf}=$ fluid intelligence; $\mathrm{AV}-\mathrm{Span} \mathrm{R}_{\mathrm{Res}}=$ residualized auditory-verbal span; $\mathrm{M}-\mathrm{Span}_{\text {Res }}=$ residualized movement span; $\mathrm{WMC}=$ working memory capacity; SL = sign learning; $\mathrm{WL}=$ word learning; $\mathrm{dLTM}=$ declarative $\mathrm{LTM}$ ability; Reading = test of reading comprehension; Vocab $=$ extended range administration test; Gram = grammar and usage test; Info $=$ information test; Ravens $=$ Raven's Advanced Progressive Matrices, Set II; SLAT = spatial learning ability test; NumSeries = number series; LetSets $=$ letter sets; NSPT $=$ nonsign paired task; ProSign $=$ Probed Sign recognition task; SignCon $=$ sign configuration task; OSpan = operation span; SymSpan = symmetry span; RoSpan = rotation span; ASL-SL = ASL sign learning; PSL = pseudosign learning; $3 \mathrm{TSL}=$ three-term sign learning; DPSL = delayed pseudosign learning; LetSpan $=$ letter span; NWRec $=$ Nonword Recognition; NWSpan $=$ Nonword Span; TWL $=$ Turkish word learning; $\mathrm{PWL}=$ pseudosign learning; $3 \mathrm{TWL}=$ three-term word learning; $\mathrm{DPWL}=$ delayed word learning 
Table 3. Correlations (with standard errors) amongst latent variables

\begin{tabular}{llllll}
\hline & Gc & Gf & AV-Span & M-Span & WMC \\
\hline Gf & $.78(.04)$ & & & & \\
AV-Span & $.37(.08)$ & $.20(.08)$ & & & \\
M-Span & $.38(.08)$ & $.29(.08)$ & $.53(.09)$ & & \\
WMC & $.57(.07)$ & $.80(.05)$ & -- & -- & \\
dLTM & $.68(.05)$ & $.79(.04)$ & $.49(.07)$ & $.54(.07)$ & $.60(.06)$ \\
\hline
\end{tabular}

Note: $\mathrm{Gf}=$ fluid intelligence; $\mathrm{Gc}=$ crystallized intelligence; $\mathrm{AV}$-span res $=$ residualized auditory-verbal span; M$\mathrm{Span}_{\mathrm{res}}=$ residualized movement span; $\mathrm{WMC}=$ working memory capacity; $\mathrm{dLTM}=$ declarative LTM ability.

Next, structural equation models were fitted to examine the effects of WMC, STM span, and dLTM ability on Gf and Gc. To facilitate interpretation, variables were entered in a hierarchical fashion with the first model consisting of the immediate memory and intelligence factors and the next adding dLTM ability. The first model (Figure 7) fit well, $X^{2}(105)=186.30$, $\mathrm{p}<.000, \mathrm{CFI}=.958, \mathrm{SRMR}=.042, \mathrm{RMSEA}=.057(90 \% \mathrm{CI}=.044, .071)$. The residualized auditory-verbal span factor, WMC, and the residualized movement span factor accounted for a significant proportion of variance in Gc; WMC and the residualized movement span factor accounted for variance in Gf. In all, the immediate memory factors accounted for $52 \%$ and $72 \%$ of the variance in Gc and Gf, respectively.

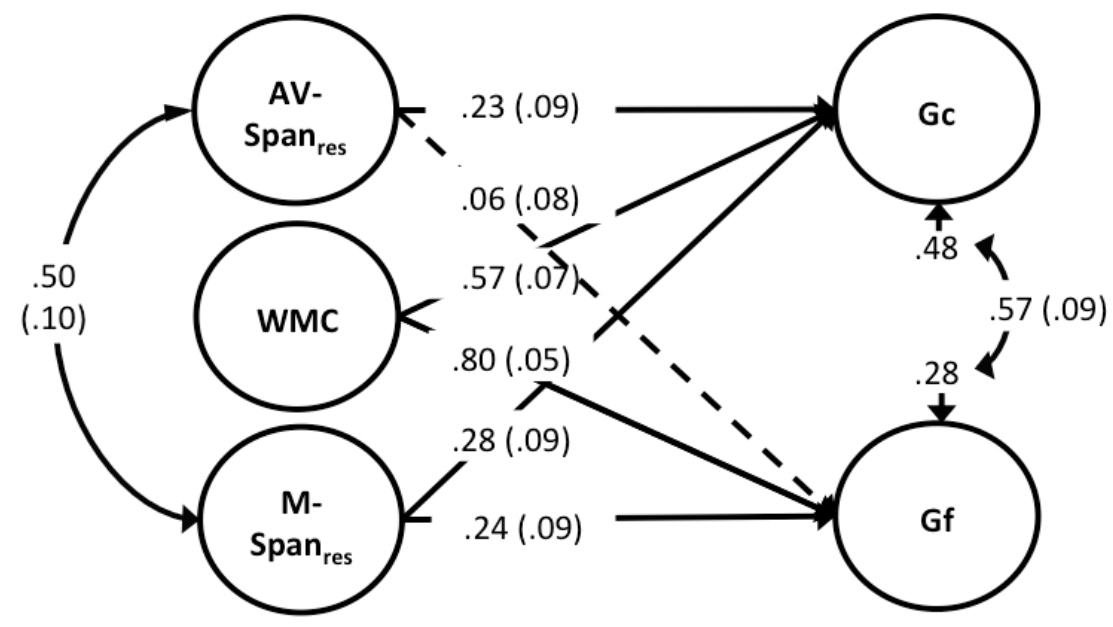

Figure 7. Model 1: immediate memory factors, Gc, and Gf. Path coefficients are standardized. Numbers in parentheses are standard errors. Gc = crystallized intelligence; $\mathrm{Gf}=$ fluid intelligence; AV-Span Res $_{\text {= }}$ residualized auditory-verbal span; $\mathrm{M}$-Span $\mathrm{Ses}_{\text {Re }}$ residualized movement span; WMC = working memory capacity 
The second model (Figure 8 ) included dLTM ability. The model also fit the data well, $X^{2}$ $(254)=419.015, \mathrm{p}<.000, \mathrm{CFI}=.954, \mathrm{SRMR}=.043, \mathrm{RMSEA}=.052(90 \% \mathrm{CI}=.043, .061)$.

WMC and dLTM accounted for a significant proportion of variance in Gc as well as Gf; no other variable was significant. In all, the variables accounted for $53 \%$ and $79 \%$ of the variance in Gc and Gf, respectively.

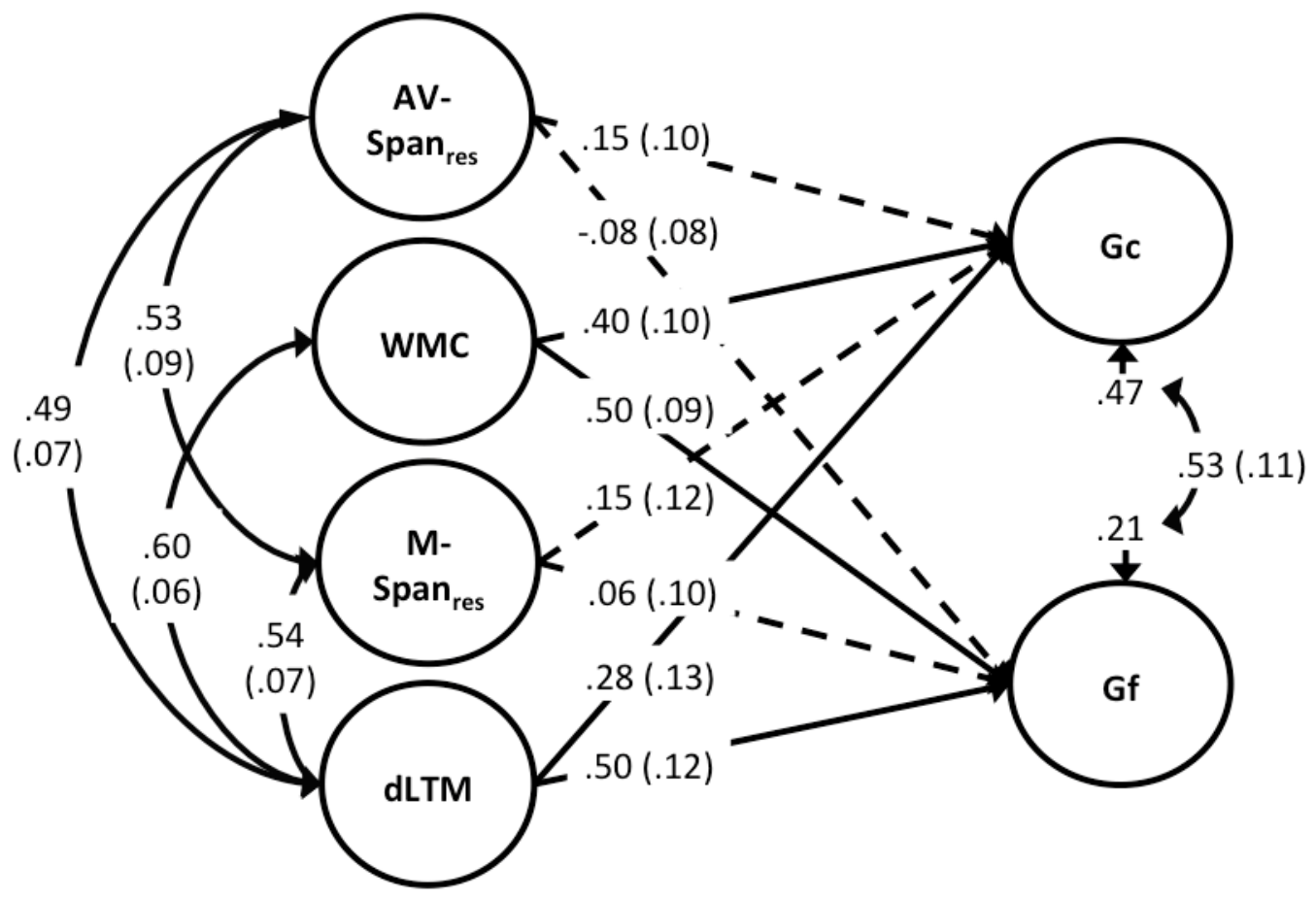

Figure 8. Model 2: Immediate and long-term memory factors, Gc, and Gf. Path coefficients are standardized. Numbers in parentheses are standard errors. Gf = fluid intelligence; Gc = crystallized intelligence; $\mathrm{AV}$-span $\mathrm{res}_{\text {res }}=$ residualized auditory-verbal span; $\mathrm{M}-\mathrm{Span}_{\mathrm{res}}=$ residualized movement span; $\mathrm{WMC}=$ working memory capacity; $\mathrm{dLTM}=$ declarative LTM ability.

Exploratory analyses. Two post-hoc analyses were conducted to gain further insight into the observed relationships (see Appendix A and B for new measurement models and latent variable correlations, respectively). According to Cattell (1987), Gf has a direct influence on Gc, therefore, in the first exploratory analysis, Gf was included as a predictor. Model fit was good, $X^{2}$ $(254)=419.02, \mathrm{p}<.000, \mathrm{CFI}=.954, \mathrm{SRMR}=.043, \mathrm{RMSEA}=.052(90 \% \mathrm{CI}=.043, .061)$. The 
residualized auditory-verbal span factor and Gf significantly accounted for variance in Gc. In all, the predictors accounted for $67 \%$ of the variance in Gc.

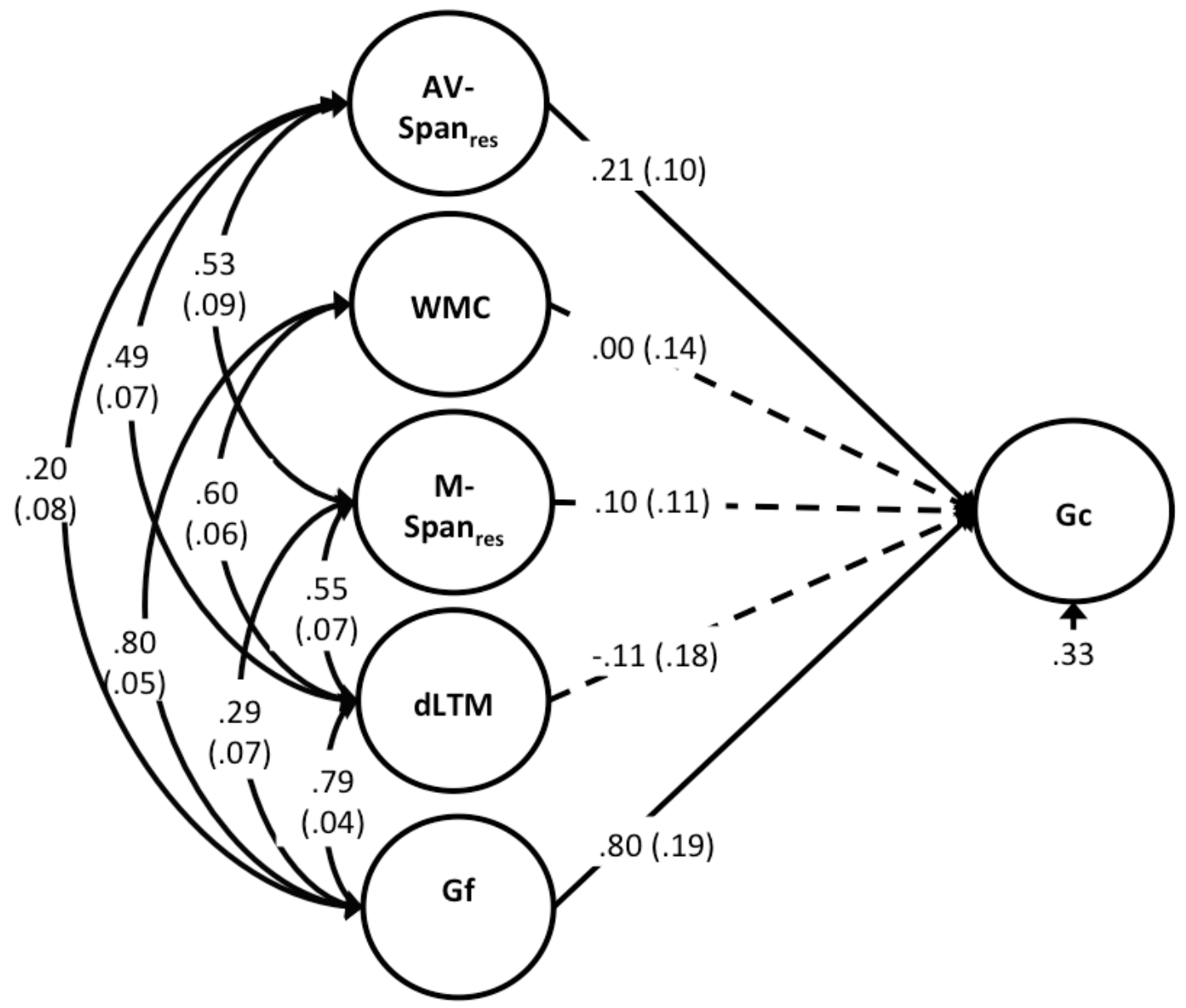

Figure 9. Model 3: adding Gf as a predictor. Path coefficients are standardized. Numbers in parentheses are standard errors. Gf = fluid intelligence; $\mathrm{Gc}=$ crystallized intelligence; $\mathrm{AV}$-span res $_{\text {re }}$ residualized auditory-verbal span; $\mathrm{M}-\mathrm{Span}_{\mathrm{res}}=$ residualized movement span; $\mathrm{WMC}=$ working memory capacity; $\mathrm{dLTM}=$ declarative LTM ability.

The purpose of the second exploratory model was to investigate effects of the memory factors on residualized Gc and Gf factors, with variance common to both Gf and Gc partialled out. A bifactor model was designated such that all Gc and Gf tasks loaded onto a general factor as well as specific Gc and Gf factors, as appropriate, however, this model did not converge. Next, in accord with Cattell's (1987) investment theory, a model was designated with all 
intelligence tasks loaded on one general factor and Gc tasks additionally loaded on a specific factor. The model converged and fit well, $X^{2}(251)=416.18, \mathrm{p}<.000, \mathrm{CFI}=.955, \mathrm{SRMR}=.043$, RMSEA $=.053(90 \% \mathrm{CI}=.043, .061)$. WMC and dLTM ability accounted for a significant proportion of variance in the general factor, however, none of the paths between the memory factors and the residualized Gc factor were significant.

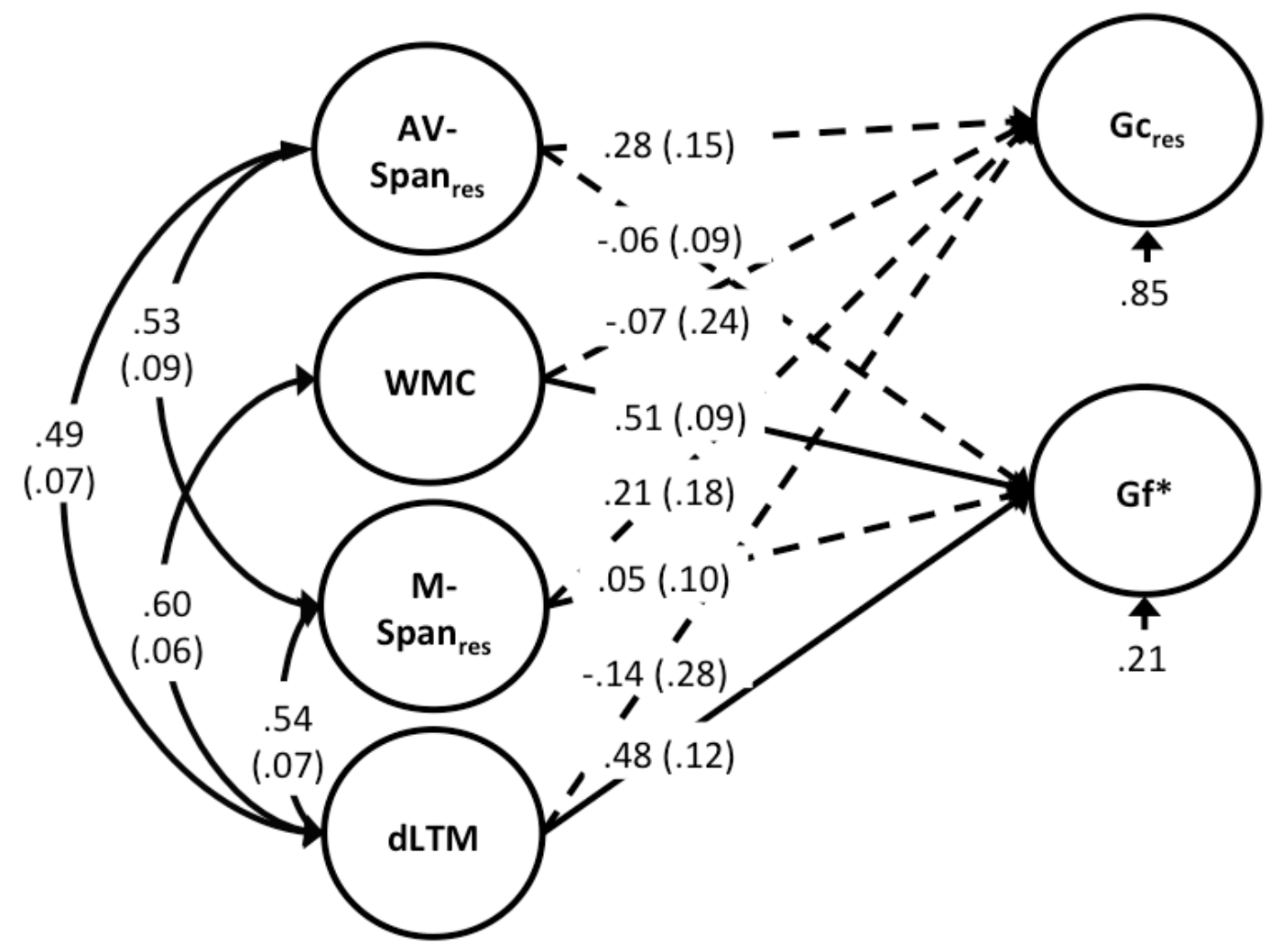

Figure 10. Model 4: predicting a general intelligence factor and a residualized Gc factor. Path coefficients are standardized. Numbers in parentheses are standard errors. Gf* = general factor composed of common variance amongst $\mathrm{Gf}$ and $\mathrm{Gc}$ tasks; $\mathrm{Gc}_{\mathrm{res}}=$ specific factor composed of common variance in Gc tasks after controlling for Gf; $\mathrm{AV}$-span res $_{\text {r }}=$ residualized auditory-verbal span; $\mathrm{M}-\mathrm{Span}_{\text {res }}=$ residualized movement span; WMC $=$ working memory capacity; $\mathrm{dLTM}=$ declarative LTM ability. 


\section{Discussion}

In line with prior research, WMC and dLTM ability independently accounted for variance in Gf (e.g., Kaufman et al., 2009; Unsworth et al., 2009); notably, these same factors also accounted for variance in Gc. The results of the exploratory analyses, however, raise some interesting issues that may—depending on the weight given to these results—alter interpretations. Because of this, I begin by reviewing the results as they relate to $\mathrm{Gc}$, the factor most impacted by the exploratory analyses. I further divide this discussion of $\mathrm{Gc}$ and memory based on the planned and exploratory results. This discussion necessarily involves Gf, however, I discuss the results as they specifically relate to Gf in a subsequent subsection.

\section{Memory and Its Relation to Crystallized Intelligence}

Interpreting the results of the planned analyses. WMC was expected to predict individual differences in Gc because WMC reflects a domain-general ability to maintain attention on relevant information and this, in turn, facilitates encoding and other cognitive activities. Auditory-verbal span was expected to account for variance in Gc over and above WMC because of overlap in domain-specific (i.e., verbal) processes. Model 1 (Figure 7) confirmed these expectations.

Model 2 (Figure 8) was intended to assess the effect of dLTM ability. As expected, dLTM ability accounted for variance in Gc over and above the immediate memory factors, however, unexpectedly, the auditory-verbal factor was no longer significant (Figure 8). It is likely that the dLTM ability factor, though intended to be amodal, captured auditory-verbal processes. A prior study using this data (Martinez \& Singleton, 2019) revealed that dLTM ability could be modeled as a general factor and a specific factor. The general factor accounted for processes common to word and sign learning while the specific factor accounted for residual 
variance in sign learning. The authors argued that when a word is presented with an unknown lexical item, whether signed or spoken, hearing individuals rely on speech-based verbal mediation, but sign learning employs additional processes - the general factor captured the speech-based processes common to all associative tasks while the specific factor captured those exclusive to sign learning. In the present study, the dLTM ability factor is essentially the general factor estimated in the prior study and therefore likely captured verbal speech-based processes common to all the associative learning tasks used here.

In contrast to auditory-verbal span, no relation between movement span and Gc was expected, particularly when WMC was accounted for. The results, however, showed that prior to adding in dLTM, movement span was a significant predictor. The fact that movement span was a significant predictor of Gc indicates that non-verbal STM tasks assess processes relevant to complex cognition that are not captured by auditory-verbal span or WMC tasks. It has been suggested that the relative novelty of non-verbal tasks likely increases demands on Gf, as individuals are unlikely to have ready-made procedures for handling such tasks, they must generate and test some number of strategies and this likely relies on Gf (Miyake, Friedman, Rettinger, Shah, \& Hegarty, 2001). As indicated in the review (and evidenced in the results of the exploratory analyses), Gc is partly determined by Gf, thus any task that assesses Gf should also account for variance in Gc.

Why then did incorporating dLTM ability render the path between the movement span factor and Gc insignificant (Model 2; Figure 8)? In this study, in order to minimize differences in strategy use during associative learning, participants were asked to use an elaborative rehearsal strategy and several illustrations were provided. As argued elsewhere (Martinez \& Singleton, 2019), elaborative rehearsal likely depends heavily on Gf. For example, to remember that the 
Turkish word doğum means birth, one may note that doğum sounds somewhat similar to the English word dome and a dome is a convex structure visually similar to a pregnant women's abdomen — pregnancy being a precursor to birth. The ability to perceive relations - in this case, a sound similarity, visual similarity, and finally a temporal relation-is the very definition of Gf (Cattell, 1943, 1987). Of course, it is also assumed that in addition to reasoning processes, dLTM ability assesses long-term storage processes that are critical to the development of Gc.

Incorporating the results of the exploratory analyses. The results of the exploratory analyses suggest that WMC and ILTM ability explain variance in Gc that is due to the investment of Gf - they do not account for any variance in Gc exclusive of Gf. These results should not be taken to mean that immediate memory and LTM are irrelevant to Gc. Gf is a critical component of Gc, thus any factor that accounts for Gf is critical to Gc. Moreover, from a theoretical standpoint, it seems highly probable that immediate memory and LTM are related to the acquisition, retention, and use of knowledge and therefore to Gc. More likely, what the results of the exploratory analyses reveal is that Gf mediates the effects of WMC and dLTM ability on Gc - that is, immediate and long-term memory abilities are related to Gc to the extent that they facilitate Gf performance. Nevertheless, the implication is that memory abilities only indirectly affect Gc. Furthermore, from a practical standpoint, these results suggest that applied researchers interested in Gc can forgo assessing WMC and dLTM ability when the option of assessing Gf is available.

One other noteworthy outcome was that in Model 3 (Figure 9), the auditory-verbal span factor was significant. While this result is in accord with what was predicted, it is inconsistent with other results and thus it seems even more hazardous to interpret. 
Of course, these results are exploratory and, additionally, there are a number of potential methodological issues that may have resulted in spurious results. For example, it is possible that, in Model 4 (Figure 10), none of the predictors directly accounted for a significant proportion of variance in the residualized Gc factor because, in removing the variance in Gc due to Gf, factor loadings decreased and measurement error increased, decreasing the power to detect an effect. Note, for example, that in Model 4, the path coefficient between the residualized auditory-verbal span factor and the residualized Gc factor is sizeable but not statistically significant.

Another possible problem is that the tasks chosen to index Gc may have exaggerated the relationship between Gc and Gf. In the present study, the majority of the Gc indicators were linguistic variables, however, Schipolowski, Wilhelm, and Schroeders (2014) reported that while linguistic and more scholastic measures of knowledge (e.g., knowledge of history) are highly correlated (see also Rolfhus \& Ackerman, 1999), scholastic knowledge shows a slightly lower relationship with Gf. Perhaps significant paths from the memory variables to the residualized Gc factor would have been observed had more indicators of domain-specific knowledge been included.

Finally, another problem raised by the results of the exploratory analyses concerns the composition of the dLTM factor. It was anticipated that Gf would facilitate dLTM performance and this would bolster the relationship between ILTM ability and Gf, but long-term storage processes - more reliably assessed by LTM tasks—-would also contribute to Gc performance. Yet, Model 3 (Figure 9) indicated that when Gf was included as a predictor alongside dLTM ability, the path between dLTM ability and Gc was no longer significant. In hindsight, it seems possible that individual differences in Gf overshadowed individual differences in long-term 
storage ability - those individuals who generated the best elaborations were also the individuals who recalled the most information, regardless of storage ability.

This possibility raises the issue of strategy use. Few researchers investigating the role of dLTM ability in intelligent behavior report instructing participants on strategy use, yet, research shows that there is variation in knowledge about and use of strategies (Bower \& Winzenz, 1970; Bradley \& Glenberg, 1983; Dunlosky \& Hertzog, 2000; Shaughnessy, 1981; Unsworth, 2019). Currently, it is unknown what effect strategy use has on relationships between dLTM ability and other cognitive variables.

Future research should investigate the possibility of differential relationships between dLTM ability and other cognitive abilities as a function of strategy use. In the meantime, researchers should attempt to control for strategy use. As intimated above, one way to control for strategy use is to explicitly instruct participants to use a particular strategy. Researchers should also consider using a variety of dLTM paradigms (a limitation of the present study). Presumably some paradigms will be more or less amenable to strategy use and, in any case, a strategy that works in one situation may not work in another (e.g., see Jensen \& Rohwer, 1963). In this way, measurement error due to strategy use can be decreased.

General remarks. Regardless of the results of the exploratory analyses, the planned analyses indicated that, compared to Gf, a much smaller proportion of variance in Gc is captured by memory abilities. This is almost certainly due, in part, to the greater involvement of environmental and other non-cognitive factors (e.g., personality, interests) in Gc compared to Gf (Ackerman \& Heggestad, 1997; Cattell, 1943, 1987; Goff \& Ackerman, 1992; Rolfhus \& Ackerman, 1999; Von Stumm \& Ackerman, 2013). Still, other cognitive abilities (such as 
processing speed; Ackerman, 1988; Kyllonen et al., 1991; Kyllonen \& Woltz, 1989) likely capture differences in Gc and should be explored in future research.

\section{Memory and Its Relation to Fluid Intelligence}

The planned analysis offer some support for the executive attention account (Engle, 2002) and dual-component model (Unsworth \& Engle, 2006, 2007b). According to the executive attention account, immediate memory tasks relate to Gf to the extent that they depend on a domain-general ability to maintain attention on relevant information- the relation is not due to domain-specific storage and rehearsal processes (cf. Colom, Rebollo, et al., 2006). The dualcomponent model further specifies that LTM retrieval also contributes to the predictive power of WMC paradigms (e.g., complex span), as both WMC and Gf tasks tend to overload immediate memory and critical information must be retrieved from LTM.

The first model (Figure 7) indicated that WMC, modeled as the variance common to all of the immediate memory tasks, independently accounted for variance in Gf. Unexpectedly, however, so did movement span; however, when dLTM ability was added as a predictor (Figure 8), it and WMC independently accounted for variance in Gf but movement span no longer did. As noted in the discussion above, it is likely that movement span tasks capture control processes needed to work with unfamiliar material and this is why it related to Gf over and above WMC, not because of any domain-specific processes.

The exploratory analyses, however, challenge the presumed role of LTM processes in Gf performance. On the one hand, dLTM ability tasks, such as the associative learning tasks used here, are more reliable and comprehensive measures of LTM processes and thus go above and beyond immediate memory tasks in accounting for variance in Gf-for example, dLTM ability tasks may capture processes that support online learning (Harrison et al., 2015; Ren et al., 2014). 
On the other hand, the discussion above on the role of Gf in ALTM ability raises the possibility that the relationship between dLTM ability and Gf may have been entirely due to Gf determining dLTM ability, not the other way around. Differences in strategy use due to sample and/or task characteristics may explain why some report that dLTM ability accounts for variance in Gf over and above WMC (e.g., Kaufman et al., 2009) while others do not (e.g., Wilhelm et al., 2013). It may be that when participants are inclined to use elaborative rehearsal strategies, the effect is obtained, as dLTM ability captures Gf processes. However, when individuals are inclined to use rote rehearsal, then, dLTM ability tasks may capture many of the same processes as immediate memory tasks.

Finally, note that in this study, there was evidence for the equivalence of Gf with a general intelligence factor, supporting Cattell's (1987) investment theory. According to Cattell (1987, p. 142), Gf is likely to explain a substantial proportion of variance in Gc and manifest as a general factor in young individuals who have shared educational and other opportunities. In this study, the sample was young (mean age 21.24 years, $\mathrm{SD}=3.57)$ and most $(94.8 \%)$ reported attending or having attended a postsecondary school. Moreover, an inclusion criterion was that individuals had resided in the USA since the age of 5, thus, presumably, participants had a fairly homogenous educational experience (though, of course, inequalities do exist in the USA; Flores, 2007; Ladson-Billings, 2006). Appropriately, the relationships between this general intelligence factor (labeled Gf* in Figure 10) and the memory factors were the same as those between the memory factors and Gf.

\section{Conclusion}

Overall, the results of this study indicate that WMC and ALTM ability are predictive of Gc and Gf. The exploratory analyses, however, suggest that the reason these factors are 
predictive of Gc is because they account for the variance in Gc that is due to the investment of Gf. The exploratory analyses also raise the possibility that the reason LTM tasks are predictive of Gf is because such tasks depend on reasoning abilities, not because Gf performance depends on long-term storage. Given the prominence of intelligence and memory in psychological theory and daily life activities, researchers should continue investigating relationships amongst these factors, particularly those, such as Gc and dLTM ability, which tend to receive less attention in research on intelligence. 


\section{REFERENCES}

Ackerman, P. L. (1988). Determinants of individual differences during skill acquisition: Cognitive abilities and information processing. Journal of Experimental Psychology: General, 117(3), 288-318. doi:10.1037/0096-3445.117.3.288

Ackerman, P. L. (1996). A theory of adult intellectual development: Process, personality, interests, and knowledge. Intelligence, 22(2), 227-257. doi:https://doi.org/10.1016/S0160-2896(96)90016-1

Ackerman, P. L. (2000). Domain-Specific Knowledge as the "Dark Matter" of Adult Intelligence: Gf/Gc, Personality and Interest Correlates. The Journals of Gerontology: Series B, 55(2), P69-P84. doi:10.1093/geronb/55.2.P69

Ackerman, P. L., Beier, M. E., \& Boyle, M. O. (2005). Working Memory and Intelligence: The Same or Different Constructs? Psychological Bulletin, 131(1), 30-60. doi:10.1037/0033-2909.131.1.30

Ackerman, P. L., \& Heggestad, E. D. (1997). Intelligence, personality, and interests: Evidence for overlapping traits. Psychological Bulletin, 121(2), 219-245. doi:10.1037/00332909.121.2.219

Baddeley, A. D. (1966). Short-term memory for word sequences as a function of acoustic, semantic and formal similarity. The Quarterly Journal of Experimental Psychology, 18(4), 362-365. doi:10.1080/14640746608400055

Baddeley, A. D. (1970). Effects of acoustic and semantic similarity on short-term pairedassociate learning. British Journal of Psychology, 61(3), 335-343.

Baddeley, A. D. (2012). Working memory: Theories, models, and controversies. Annual Review of Psychology, 63, 1-29. doi:10.1146/annurev-psych-120710-100422

Baddeley, A. D., \& Dale, H. C. A. (1966). The effect of semantic similarity on retroactive interference in long- and short-term memory. Journal of Verbal Learning \& Verbal Behavior, 5(5), 417-420. doi:10.1016/S0022-5371(66)80054-3

Baddeley, A. D., Gathercole, S., \& Papagno, C. (1998). The phonological loop as a language learning device. Psychological Review, 105(1), 158-173. doi:10.1037/0033295X.105.1.158

Baddeley, A. D., \& Hitch, G. (1974). Working Memory. In G. H. Bower (Ed.), Psychology of Learning and Motivation (Vol. 8, pp. 47-89): Academic Press.

Bailey, H., Dunlosky, J., \& Kane, M. J. (2008). Why does working memory span predict complex cognition? Testing the strategy affordance hypothesis. Memory \& Cognition, 36(8), 1383-1390.

Basso, A., Spinnler, H., Vallar, G., \& Zanobio, M. E. (1982). Left hemisphere damage and selective impairment of auditory verbal short-term memory: A case study. Neuropsychologia, 20(3), 263-274. doi:10.1016/0028-3932(82)90101-4

Batty, G. D., Deary, I. J., \& Gottfredson, L. S. (2007). Premorbid (early life) IQ and Later Mortality Risk: Systematic Review. Annals of Epidemiology, 17(4), 278-288. doi:10.1016/j.annepidem.2006.07.010 
Bayliss, D. M., Jarrold, C., Baddeley, A. D., \& Gunn, D. M. (2005). The relationship between short - term memory and working memory: Complex span made simple? Memory, 13(3-4), 414-421. doi:10.1080/09658210344000332

Beier, M. E., \& Ackerman, P. L. (2005). Age, Ability, and the Role of Prior Knowledge on the Acquisition of New Domain Knowledge: Promising Results in a Real-World Learning Environment. Psychology and Aging, 20(2), 341-355. doi:10.1037/08827974.20.2.341

Blajenkova, O., Kozhevnikov, M., \& Motes, M. A. (2006). Object-spatial imagery: a new selfreport imagery questionnaire. Applied Cognitive Psychology, 20(2), 239-263. doi:10.1002/acp.1182

Botvinick, M. M. (2005). Effects of domain-specific knowledge on memory for serial order. Cognition, 97(2), 135-151. doi:10.1016/j.cognition.2004.09.007

Boutwell, B. B. (2018). OPINION: 2018 Holden memorial address: Intelligence: The easy pieces (with apologies to Richard Feynman). Intelligence. doi:10.1016/j.intell.2018.07.005

Bower, G. H., \& Winzenz, D. (1970). Comparison of associative learning strategies. Psychonomic Science, 20(2), 119-120. doi:10.3758/BF03335632

Bradley, M. M., \& Glenberg, A. M. (1983). Strengthening associations: Duration, attention, or relations? Journal of Verbal Learning \& Verbal Behavior, 22(6), 650-666. doi:10.1016/S0022-5371(83)90385-7

Carpenter, P. A., Just, M. A., \& Shell, P. (1990). What one intelligence test measures: a theoretical account of the processing in the Raven Progressive Matrices Test. Psychological Review, 97(3), 404.

Carroll, J. B. (1993). Human cognitive abilities: A survey of factor-analytic studies: Cambridge University Press.

Caselli, N. K., Sehyr, Z. S., Cohen-Goldberg, A. M., \& Emmorey, K. (2016). ASL-LEX: A lexical database of American Sign Language. Behavior Research Methods, 1-18. doi:10.3758/s13428-016-0742-0

Cattell, R. B. (1943). The measurement of adult intelligence. Psychological Bulletin, 40(3), 153-193. doi:10.1037/h0059973

Cattell, R. B. (1987). Intelligence: Its structure, growth and action. Oxford, England: NorthHolland.

Christoforou, A., Espeseth, T., Davies, G., Fernandes, C. P. D., Giddaluru, S., Mattheisen, M., ... Le Hellard, S. (2014). GWAS-based pathway analysis differentiates between fluid and crystallized intelligence. Genes, Brain and Behavior, 13(7), 663-674. doi:10.1111/gbb.12152

Colom, R., Haier, R. J., Head, K., Alvarez-Linera, J., Quiroga, M. A., Shih, P. C., \& Jung, R. E. (2009). Gray Matter Correlates of Fluid, Crystallized, and Spatial Intelligence: Testing the P-FIT Model. Intelligence, 37(2), 124-135. doi:10.1016/j.intell.2008.07.007

Colom, R., Rebollo, I., Abad, F. J., \& Shih, P. C. (2006). Complex span tasks, simple span tasks, and cognitive abilities: A reanalysis of key studies. Memory \& Cognition, 34(1), 158171. doi:10.3758/bf03193395 
Colom, R., Shih, P. C., Flores-Mendoza, C., \& Quiroga, M. Á. (2006). The real relationship between short-term memory and working memory. Memory, 14(7), 804-813. doi:10.1080/09658210600680020

Conway, A. R. A., Cowan, N., Bunting, M. F., Therriault, D. J., \& Minkoff, S. R. B. (2002). A latent variable analysis of working memory capacity, short-term memory capacity, processing speed, and general fluid intelligence. Intelligence, 30(2), 163-183. doi:10.1016/S0160-2896(01)00096-4

Conway, A. R. A., Kane, M. J., Bunting, M. F., Hambrick, D. Z., Wilhelm, O., \& Engle, R. W. (2005). Working memory span tasks: A methodological review and user's guide. Psychonomic Bulletin \& Review, 12(5), 769-786.

Cowan, N. (1999). An Embedded-Processes Model of Working Memory. In A. Miyake \& P. Shah (Eds.), Models of Working Memory: Mechanisms of Active Maintenance and Executive Control (pp. 62-101). Cambridge: Cambridge University Press.

Cowan, N. (2008). What are the differences between long-term, short-term, and working memory? Progress in brain research, 169, 323-338. doi:10.1016/S00796123(07)00020-9

Cowan, N. (2017). The many faces of working memory and short-term storage. Psychonomic Bulletin \& Review, 24(4), 1158-1170. doi:10.3758/s13423-016-1191-6

Craik, F., \& Lockhart, R. S. (1972). Levels of processing: A framework for memory research. Journal of Verbal Learning \& Verbal Behavior, 11(6), 671-684. doi:10.1016/S00225371(72)80001-X

Craik, F., \& Watkins, M. J. (1973). The role of rehearsal in short-term memory. Journal of Verbal Learning and Verbal Behavior, 12(6), 599-607. doi:10.1016/S00225371(73)80039-8

Daneman, M., \& Carpenter, P. A. (1980). Individual differences in working memory and reading. Journal of Verbal Learning and Verbal Behavior, 19(4), 450-466. doi:10.1016/S0022-5371(80)90312-6

Daneman, M., \& Merikle, P. M. (1996). Working memory and language comprehension: A meta-analysis. Psychonomic Bulletin \& Review, 3(4), 422-433. doi:10.3758/bf03214546

Dang, C.-P., Braeken, J., Colom, R., Ferrer, E., \& Liu, C. (2014). Why is working memory related to intelligence? Different contributions from storage and processing. Memory, 22(4), 426-441. doi:10.1080/09658211.2013.797471

Dang, C.-P., Braeken, J., Ferrer, E., \& Liu, C. (2012). Unitary or Non-Unitary Nature of Working Memory? Evidence from Its Relation to General Fluid and Crystallized Intelligence. Intelligence, 40(5), 499-508. doi:10.1016/j.intell.2012.05.002

Diehl, M., Willis, S. L., \& Schaie, K. W. (1995). Everyday problem solving in older adults: Observational assessment and cognitive correlates. Psychology and Aging, 10(3), 478-491. doi:10.1037/0882-7974.10.3.478

Driskell, J. E., Willis, R. P., \& Copper, C. (1992). Effect of overlearning on retention. Journal of Applied Psychology, 77(5), 615-622. doi:10.1037/0021-9010.77.5.615

Dunlosky, J., \& Hertzog, C. (2000). Updating knowledge about encoding strategies: A componential analysis of learning about strategy effectiveness from task experience. Psychology and Aging, 15(3), 462-474. doi:10.1037/0882-7974.15.3.462 
Dunlosky, J., \& Kane, M. J. (2007). The contributions of strategy use to working memory span: A comparison of strategy assessment methods. The Quarterly Journal of Experimental Psychology, 60(9), 1227-1245. doi:10.1080/17470210600926075

Ekstrom, R., French, J., Harman, H., \& Dermen, D. (1976). Kit of factor-referenced cognitive tests. . Princeton, NJ: Educational Testing Service.

Embretson, S. E. (1992). Measuring and Validating Cognitive Modifiability as an Ability: A Study in the Spatial Domain. Journal of Educational Measurement, 29(1), 25-50.

Engle, R. W. (2002). Working Memory Capacity as Executive Attention. Current Directions in Psychological Science, 11(1), 19-23. doi:10.1111/1467-8721.00160

Engle, R. W. (2018). Working Memory and Executive Attention: A Revisit. Perspectives on Psychological Science, 13(2), 190-193. doi:10.1177/1745691617720478

Engle, R. W., Tuholski, S. W., Laughlin, J. E., \& Conway, A. R. A. (1999). Working memory, short-term memory, and general fluid intelligence: A latent-variable approach. Journal of Experimental Psychology: General, 128(3), 309-331. doi:10.1037/00963445.128.3.309

Ericsson, K. A., \& Kintsch, W. (1995). Long-term working memory. Psychological Review, 102(2), 211-245. doi:10.1037/0033-295X.102.2.211

Ferrer, E., \& McArdle, J. J. (2004). An experimental analysis of dynamic hypotheses about cognitive abilities and achievement from childhood to early adulthood. Developmental Psychology, 40(6), 935.

Flores, A. (2007). Examining disparities in mathematics education: Achievement gap or opportunity gap? The High School Journal, 91(1), 29-42.

Foster, J. L., Shipstead, Z., Harrison, T. L., Hicks, K. L., Redick, T. S., \& Engle, R. W. (2015). Shortened complex span tasks can reliably measure working memory capacity. Memory \& Cognition, 43(2), 226-236. doi:10.3758/s13421-014-0461-7

Gathercole, S. E. (1995). Is nonword repetition a test of phonological memory or long-term knowledge? It all depends on the nonwords. Memory \& Cognition, 23(1), 83-94. doi:10.3758/bf03210559

Gathercole, S. E., Pickering, S. J., Hall, M., \& Peaker, S. M. (2001). Dissociable lexical and phonological influences on serial recognition and serial recall. The Quarterly Journal of Experimental Psychology A: Human Experimental Psychology, 54A(1), 1-30. doi:10.1080/02724980042000002

Glanzer, M., \& Cunitz, A. R. (1966). Two storage mechanisms in free recall. Journal of verbal learning and verbal behavior., 5(4), 351-360.

Goff, M., \& Ackerman, P. L. (1992). Personality-intelligence relations: Assessment of typical intellectual engagement. Journal of Educational Psychology, 84(4), 537-552. doi:10.1037/0022-0663.84.4.537

Gordon, R. A. (1997). Everyday life as an intelligence test: Effects of intelligence and intelligence context. Intelligence, 24(1), 203-320. doi:10.1016/S01602896(97)90017-9

Gottfredson, L. S. (1997). Why g matters: The complexity of everyday life. Intelligence, 24(1), 79-132. doi:10.1016/S0160-2896(97)90014-3

Gupta, P., \& Tisdale, J. (2009). Does phonological short-term memory causally determine vocabulary learning? Toward a computational resolution of the debate. Journal of Memory and Language, 61(4), 481-502. doi:10.1016/j.jml.2009.08.001 
Gustafsson, J.-E. (1984). A Unifying Model for the Structure of Intellectual Abilities. Intelligence, 8(3), 179-203.

Gustafsson, J.-E., \& Undheim, J. O. (1992). Stability and change in broad and narrow factors of intelligence from ages 12 to 15 years. Journal of Educational Psychology, 84(2), 141.

Haavisto, M.-L., \& Lehto, J. E. (2005). Fluid/spatial and crystallized intelligence in relation to domain-specific working memory: A latent-variable approach. Learning and Individual Differences, 15(1), 1-21. doi:10.1016/j.lindif.2004.04.002

Hambrick, D. (2003). Why are some people more knowledgeable than others? A longitudinal study of knowledge acquisition. Memory \& Cognition, 31(6), 902-917. doi:10.3758/BF03196444

Harrison, T. L. (2017). N-back as a measure of working memory capacity. (PhD Dissertation), Georgia Institute of Technology. Retrieved from http://hdl.handle.net/1853/58762

Harrison, T. L., Shipstead, Z., \& Engle, R. W. (2015). Why is working memory capacity related to matrix reasoning tasks? Memory \& Cognition, 43(3), 389-396. doi:10.3758/s13421-014-0473-3

Horn, J. L., \& Cattell, R. B. (1966). Refinement and test of the theory of fluid and crystallized general intelligences. Journal of Educational Psychology, 57(5), 253-270. doi:10.1037/h0023816

Horn, J. L., \& Cattell, R. B. (1967). Age differences in fluid and crystallized intelligence. Acta Psychologica, 26, 107-129. doi:10.1016/0001-6918(67)90011-X

Horn, J. L., \& McArdle, J. J. (2007). Understanding human intelligence since Spearman. In R. Cudeck \& R. C. MacCallum (Eds.), Factor analysis at 100: Historical developments and future directions. (pp. 205-247). Mahwah, NJ, US: Lawrence Erlbaum Associates Publishers.

Hulme, C., Maughan, S., \& Brown, G. D. A. (1991). Memory for Familiar and Unfamiliar Words: Evidence for a Long-Term Memory Contribution to Short-Term Memory Span. Journal of Memory and Language, 30(6), 685-701.

Jackson, D. N. (1998). Multidimensional Aptitude Battery-II. London, Ontario, Canada: Sigma Assessment Systems.

James, W. (1890). The principles of psychology. Vol 1. New York: Holt.

Jeneson, A., \& Squire, L. R. (2012). Working memory, long-term memory, and medial temporal lobe function. Learning \& Memory, 19(1), 15-25. doi:10.1101/lm.024018.111

Jensen, A. R., \& Rohwer, W. D. (1963). Verbal mediation in paired-associate and serial learning. Journal of Verbal Learning and Verbal Behavior, 1(5), 346-352. doi:10.1016/S0022-5371(63)80015-8

Johnson, W., \& Bouchard, T. J., Jr. (2005). The structure of human intelligence: It is verbal, perceptual, and image rotation (VPR), not fluid and crystallized. Intelligence, 33(4), 393-416. doi:10.1016/j.intell.2004.12.002

Jung, R. E., \& Haier, R. J. (2007). The Parieto-Frontal Integration Theory (P-FIT) of intelligence: Converging neuroimaging evidence. Behavioral and Brain Sciences, 30(2), 135-154. doi:10.1017/S0140525X07001185

Kane, M. J., Hambrick, D. Z., Tuholski, S. W., Wilhelm, O., Payne, T. W., \& Engle, R. W. (2004). The Generality of Working Memory Capacity: A Latent-Variable Approach to Verbal 
and Visuospatial Memory Span and Reasoning. Journal of Experimental Psychology: General, 133(2), 189-217. doi:10.1037/0096-3445.133.2.189

Kaufman, S. B., DeYoung, C. G., Gray, J. R., Brown, J., \& Mackintosh, N. (2009). Associative learning predicts intelligence above and beyond working memory and processing speed. Intelligence, 37(4), 374-382. doi:10.1016/j.intell.2009.03.004

Kline, R. B. (2016). Principles and practice of structural equation modeling (4th ed.). New York, NY, US: Guilford Press.

Kovacs, K., \& Conway, A. R. A. (2016). Process Overlap Theory: A Unified Account of the General Factor of Intelligence. Psychological Inquiry, 27(3), 151-177. doi:10.1080/1047840X.2016.1153946

Kyllonen, P. C., Tirre, W. C., \& Christal, R. E. (1991). Knowledge and processing speed as determinants of associative learning. Journal of Experimental Psychology: General, 120(1), 57-79. doi:10.1037/0096-3445.120.1.57

Kyllonen, P. C., \& Woltz, D. J. (1989). Role of cognitive factors in the acquisition of cognitive skill. In R. Kanfer \& R. Cudeck (Eds.), Abilities, motivation, and methodology: The Minnesota Symposium on Learning and Individual Differences. (pp. 239-280). Hillsdale, NJ, England: Lawrence Erlbaum Associates, Inc.

La Pointe, L. B., \& Engle, R. W. (1990). Simple and Complex Word Spans as Measures of Working Memory Capacity. Journal of Experimental Psychology: Learning, Memory, and Cognition, 16(6), 1118-1133. doi:10.1037/0278-7393.16.6.1118

Ladson-Billings, G. (2006). From the achievement gap to the education debt: Understanding achievement in US schools. Educational researcher, 35(7), 3-12.

Larsen, L., Hartmann, P., \& Nyborg, H. (2008). The stability of general intelligence from early adulthood to middle-age. Intelligence, 36(1), 29-34.

Lohman, D. F. (1996). Spatial ability and g. In I. Dennis, P. Tapsfield, I. Dennis, \& P. Tapsfield (Eds.), Human abilities: Their nature and measurement. (pp. 97-116). Hillsdale, NJ, England: Lawrence Erlbaum Associates, Inc.

Majerus, S., Martinez Perez, T., \& Oberauer, K. (2012). Two distinct origins of long-term learning effects in verbal short-term memory. Journal of Memory and Language, 66(1), 38-51. doi:10.1016/j.jml.2011.07.006

Majerus, S., Norris, D., \& Patterson, K. (2007). What does a patient with semantic dementia remember in verbal short-term memory? Order and sound but not words. Cognitive Neuropsychology, 24(2), 131-151. doi:10.1080/02643290600989376

Marshalek, B., Lohman, D. F., \& Snow, R. E. (1983). The complexity continuum in the radex and hierarchical models of intelligence. Intelligence, 7(2), 107-127. doi:10.1016/0160-2896(83)90023-5

Martin, K. I., \& Ellis, N. C. (2012). The roles of phonological short-term memory and working memory in L2 grammar and vocabulary learning. Studies in second language acquisition, 34(3), 379-413. doi:10.1017/S0272263112000125

Martinez, D., \& Singleton, J. L. (2018). Predicting sign learning in hearing adults: The role of perceptual-motor (and phonological?) processes. Applied Psycholinguistics, 1-27. doi:10.1017/S0142716418000048

Martinez, D., \& Singleton, J. L. (2019). Individual differences in lexical learning across two language modalities: Sign learning, word learning, and their relationship in hearing non-signing adults. Acta Psychologica, 198.

doi:https://doi.org/10.1016/j.actpsy.2019.102892. 
McDonald, R. P. (1999). Test theory: A unified treatment: Psychology Press.

Miyake, A., Friedman, N. P., Rettinger, D. A., Shah, P., \& Hegarty, M. (2001). How are visuospatial working memory, executive functioning, and spatial abilities related? A latent-variable analysis. Journal of Experimental Psychology: General, 130(4), 621640. doi:10.1037/0096-3445.130.4.621

Moehring, A., Schroeders, U., \& Wilhelm, O. (2018). Knowledge Is Power for Medical Assistants: Crystallized and Fluid Intelligence As Predictors of Vocational Knowledge. Frontiers in Psychology, 9(28). doi:10.3389/fpsyg.2018.00028

Mogle, J. A., Lovett, B. J., Stawski, R. S., \& Sliwinski, M. J. (2008). What's so special about working memory? An examination of the relationships among working memory, secondary memory, and fluid intelligence. Psychological Science, 19(11), 1071-1077. doi:10.1111/j.1467-9280.2008.02202.x

Newman-Norlund, R. D., Frey, S. H., Petitto, L.-A., \& Grafton, S. T. (2006). Anatomical Substrates of Visual and Auditory Miniature Second-language Learning. Journal of Cognitive Neuroscience, 18(12), 1984-1997.

Oberauer, K. (2002). Access to information in working memory: exploring the focus of attention. Journal of experimental psychology. Learning, memory, and cognition, 28(3), 411. doi:10.1037/0278-7393.28.3.411

Oberauer, K., Lewandowsky, S., Avh, E., Brown, G. D. A., Conway, A. R. A., Cowan, N., .. . Ward, G. (2018). Benchmarks for models of short-term and working memory. Psychological Bulletin, 144(9), 885-958.

Oberauer, K., Lewandowsky, S., Farrell, S., Jarrold, C., \& Greaves, M. (2012). Modeling working memory: An interference model of complex span. Psychonomic Bulletin \& Review, 19(5), 779-819. doi:10.3758/s13423-012-0272-4

Oberauer, K., Süß, H.-M., Wilhelm, O., \& Sander, N. (2007). Individual differences in working memory capacity and reasoning ability. In A. R. A. Conway, C. Jarrold, M. J. Kane, J. N. Towse, A. R. A. Conway, C. Jarrold, M. J. Kane, \& J. N. Towse (Eds.), Variation in working memory. (pp. 49-75). New York, NY, US: Oxford University Press.

Papagno, C., \& Vallar, G. (1995). To learn or not to learn: Vocabulary in foreign languages and the problem with phonological memory. In R. Campbell \& M. A. Conway (Eds.), Broken memories: Case studies in memory impairment. (pp. 334-343). Malden: Blackwell Publishing.

Postlethwaite, B. E. (2011). Fluid abilty, crystallized ability, and performance across multiple domains: A meta-analysis. (Doctoral dissertation), University of Iowa. Retrieved from https://ir.uiowa.edu/etd/1255/

R: A language and environment for statistical computing. (2013). Retrieved from

Raven, J., Raven, J. C., \& Court, J. H. (1998). Manual for Raven's Advanced Progressive Matrices and Vocabulary Scales. San Antonio, TX: Harcourt Assessment.

Reisberg, D., Rappaport, I., \& O'Shaughnessy, M. (1984). Limits of working memory: The digit digit-span. Journal of Experimental Psychology: Learning, Memory, and Cognition, 10(2), 203-221. doi:10.1037/0278-7393.10.2.203

Ren, X., Wang, T., Altmeyer, M., \& Schweizer, K. (2014). A learning-based account of fluid intelligence from the perspective of the position effect. Learning and Individual Differences, 31, 30-35. doi:10.1016/j.lindif.2014.01.002 
Rolfhus, E. L., \& Ackerman, P. L. (1999). Assessing individual differences in knowledge: Knowledge, intelligence, and related traits. Journal of Educational Psychology, 91(3), 511-526. doi:10.1037/0022-0663.91.3.511

Rosseel, Y. (2012). Lavaan: An R package for structural equation modeling and more. Version 0.5-12 (BETA). Journal of Statistical Software, 48(2), 1-36.

Salthouse, T. A. (2004). Localizing age-related individual differences in a hierarchical structure. Intelligence, 32(6), 541-561. doi:10.1016/j.intell.2004.07.003

Schipolowski, S., Wilhelm, O., \& Schroeders, U. (2014). On the nature of crystallized intelligence: The relationship between verbal ability and factual knowledge. Intelligence, 46, 156-168. doi:10.1016/j.intell.2014.05.014

Schneider, W., Eschman, A., \& Zuccolotto, A. (2002). E-Prime reference guide. Pittsburgh, PA: Psychology Software Tools Inc.

Schneider, W. J., \& McGrew, K. S. (2018). The Cattell-Horn-Carroll theory of cognitive abilities Contemporary intellectual assessment: Theories, tests, and issues, 4th ed. (pp. 73-163). New York, NY, US: The Guilford Press.

Schroeders, U., Schipolowski, S., \& Wilhelm, O. (2015). Age-related changes in the mean and covariance structure of fluid and crystallized intelligence in childhood and adolescence. Intelligence, 48, 15-29. doi:10.1016/j.intell.2014.10.006

Schweickert, R. (1993). A multinomial processing tree model for degradation and redintegration in immediate recall. Memory \& Cognition, 21(2), 168-175. doi:10.3758/bf03202729

Scoville, W. B., \& Milner, B. (1957). Loss of recent memory after bilateral hippocampal lesions. Journal of Neurology, Neurosurgery, and Psychiatry, 20(1), 11-21.

Shaughnessy, J. J. (1981). Memory monitoring accuracy and modification of rehearsal strategies. Journal of Verbal Learning and Verbal Behavior, 20(2), 216-230. doi:10.1016/S0022-5371(81)90389-3

Shelton, J. T., Elliott, E. M., Matthews, R. A., Hill, B. D., \& Gouvier, W. D. (2010). The relationships of working memory, secondary memory, and general fluid intelligence: Working memory is special. Journal of Experimental Psychology: Learning, Memory, and Cognition, 36(3), 813-820. doi:10.1037/a0019046

Shiffrin, R. M., \& Atkinson, R. C. (1969). Storage and retrieval processes in long-term memory. Psychological Review, 76(2), 179-193. doi:10.1037/h0027277

Shipstead, Z., \& Engle, R. W. (2013). Interference within the focus of attention: Working memory tasks reflect more than temporary maintenance. Journal of Experimental Psychology: Learning, Memory, and Cognition, 39(1), 277.

Shipstead, Z., Harrison, T., \& Engle, R. W. (2016). Working memory capacity and fluid intelligence: Maintenance and disengagement. Perspectives on Psychological Science, 11(6), 771-799. doi:doi:10.1177/1745691616650647

Shipstead, Z., Lindsey, D. R. B., Marshall, R. L., \& Engle, R. W. (2014). The mechanisms of working memory capacity: Primary memory, secondary memory, and attention control. Journal of Memory and Language, 72, 116-141. doi:10.1016/j.jml.2014.01.004

Spearman, C. (1904). "General Intelligence," Objectively Determined and Measured. The American Journal of Psychology, 15(2), 201-292. doi:10.2307/1412107

Squire, L. R., Knowlton, B., \& Musen, G. (1993). The structure and organization of memory. Annual Review of Psychology, 44(1), 453-495. 
Sternberg, R., \& Kalmar, D. (1997). When will the milk spoil? Everyday induction in human intelligence. Intelligence, 24(3), 185-203.

Tamez, E., Myerson, J., \& Hale, S. (2008). Learning, working memory, and intelligence revisited. Behavioural Processes, 78(2), 240-245. doi:10.1016/j.beproc.2008.01.008

Thorsen, C., Gustafsson, J.-E., \& Cliffordson, C. (2014). The influence of fluid and crystallized intelligence on the development of knowledge and skills. The British Journal of Educational Psychology, 84(Pt 4), 556-570. doi:10.1111/bjep.12041

Thurstone, L. L. (1938). Primary Mental Abilities: Psychometric Monographs.

Underwood, B. J., Boruch, R. F., \& Malmi, R. A. (1978). Composition of episodic memory. Journal of Experimental Psychology: General, 107(4), 393-419. doi:10.1037/00963445.107.4.393

Unsworth, N. (2010). On the division of working memory and long-term memory and their relation to intelligence: A latent variable approach. Acta Psychologica, 134(1), 16-28. doi:10.1016/j.actpsy.2009.11.010

Unsworth, N. (2019). Individual differences in long-term memory. Psychological Bulletin, 145(1), 79-139. doi:10.1037/bul0000176

Unsworth, N., Brewer, G. A., \& Spillers, G. J. (2009). There's more to the working memory capacity-fluid intelligence relationship than just secondary memory. Psychonomic Bulletin \& Review, 16(5), 931-937. doi:10.3758/PBR.16.5.931

Unsworth, N., \& Engle, R. W. (2006). Simple and Complex Memory Spans and Their Relation to Fluid Abilities: Evidence from List-Length Effects. Journal of Memory and Language, 54(1), 68-80. doi:10.1016/j.jml.2005.06.003

Unsworth, N., \& Engle, R. W. (2007a). The nature of individual differences in working memory capacity: Active maintenance in primary memory and controlled search from secondary memory. Psychological Review, 114(1), 104-132. doi:10.1037/0033295X.114.1.104

Unsworth, N., \& Engle, R. W. (2007b). On the Division of Short-Term and Working Memory: An Examination of Simple and Complex Span and Their Relation to Higher Order Abilities. Psychological Bulletin, 133(6), 1038-1066. doi:10.1037/00332909.133.6.1038

Unsworth, N., \& Spillers, G. J. (2010). Working memory capacity: Attention control, secondary memory, or both? A direct test of the dual-component model. Journal of Memory and Language, 62(4), 392-406.

Valentin Kvist, A., \& Gustafsson, J.-E. (2008). The relation between fluid intelligence and the general factor as a function of cultural background: A test of Cattell's Investment theory. Intelligence, 36(5), 422-436. doi:10.1016/j.intell.2007.08.004

Van Der Maas, H. L. J., Dolan, C. V., Grasman, R. P. P. P., Wicherts, J. M., Huizenga, H. M., \& Raijmakers, M. E. J. (2006). A dynamical model of general intelligence: The positive manifold of intelligence by mutualism. Psychological Review, 113(4), 842-861. doi:10.1037/0033-295X.113.4.842

Van Der Maas, H. L. J., Kan, K.-J., Marsman, M., \& Stevenson, C. E. (2017). Network Models for Cognitive Development and Intelligence. Journal of Intelligence, 5(2), 16.

Verhagen, J., \& Leseman, P. (2016). How do verbal short-term memory and working memory relate to the acquisition of vocabulary and grammar? A comparison between first and second language learners. Journal of Experimental Child Psychology, 141, 65-82. doi:10.1016/j.jecp.2015.06.015 
Von Stumm, S., \& Ackerman, P. L. (2013). Investment and Intellect: A Review and MetaAnalysis. Psychological Bulletin, 139(4), 841-869. doi:10.1037/a0030746

Warrington, E. K., \& Shallice, T. (1969). The selective impairment of auditory verbal shortterm memory. Brain: A Journal of Neurology, 92(4), 885-896. doi:10.1093/brain/92.4.885

Waugh, N. C., \& Norman, D. A. (1965). Primary memory. Psychological Review, 72(2), 89104. doi: $10.1037 / \mathrm{h} 0021797$

Wilhelm, O., Hildebrandt, A., \& Oberauer, K. (2013). What is working memory capacity, and how can we measure it? Frontiers in Psychology, 4, 433. doi:10.3389/fpsyg.2013.00433

Williams, B. A., \& Pearlberg, S. L. (2006). Learning of three-term contingencies correlates with Raven scores, but not with measures of cognitive processing. Intelligence, 34(2), 177-191. doi:10.1016/j.intell.2005.03.007

Williams, J. T., Darcy, I., \& Newman, S. D. (2016). Modality-specific processing precedes amodal linguistic processing during L2 sign language acquisition: A longitudinal study. Cortex: A Journal Devoted to the Study of the Nervous System and Behavior, 75, 56-67. doi:10.1016/j.cortex.2015.11.015

Williams, P. C., McCallum, R. S., \& Reed, M. T. (1996). Predictive Validity of the Cattell-Horn Gf-Gc Constructs to Achievement. Assessment, 3(1), 43-51. doi:doi:10.1177/107319119600300105

Woodward, A. J., Macken, W. J., \& Jones, D. M. (2008). Linguistic familiarity in short-term memory: A role for (co-)articulatory fluency? Journal of Memory and Language, 58(1), 48-65. doi:10.1016/j.jml.2007.07.002

Wraw, C., Der, G., Gale, C. R., \& Deary, I. J. (2018). Intelligence in youth and health behaviours in middle age. Intelligence, 69, 71-86. doi:10.1016/j.intell.2018.04.005 
Appendix A

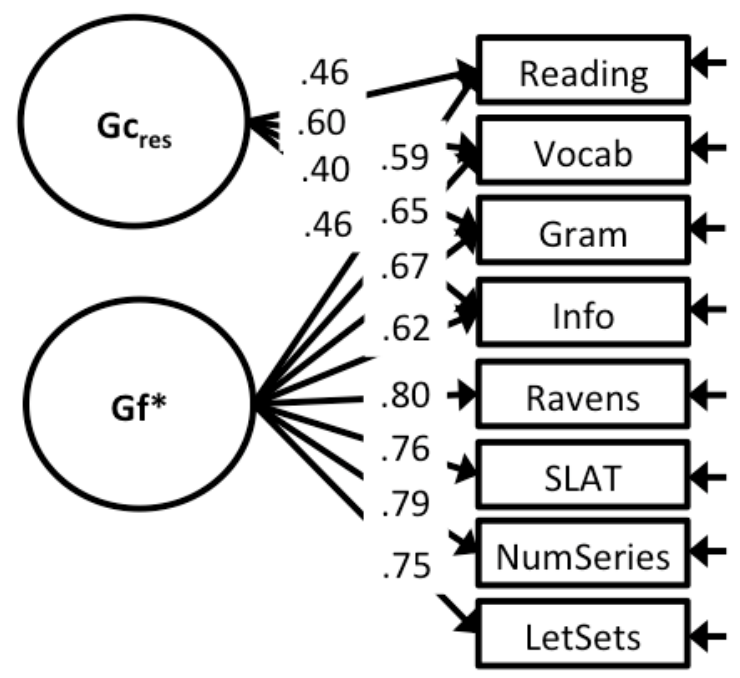

Figure A1. Factor loadings for those variables in Model 4 that were modeled differently. 


\section{Appendix B}

Table B1. Latent variable correlations (and standard errors) corresponding to Model 4

\begin{tabular}{|c|c|c|c|c|c|}
\hline & Gcres & Gf* & AV-Span ${ }_{\text {res }}$ & M-Span res & WMC \\
\hline Gf* & --- & & & & \\
\hline AV-Span & $.34(.10)$ & $20(.08)$ & & & \\
\hline M-Span ${ }_{\text {res }}$ & $.30(.12)$ & $28(.08)$ & $.53(.09)$ & & \\
\hline WMC & $-.11(.08)$ & . $80(.05)$ & --- & --- & \\
\hline dLTM ability & $.11(.07)$ & $.79(.04)$ & $.49(.07)$ & $.54(.07)$ & $.60(.06)$ \\
\hline
\end{tabular}

